Ocean Dynamics

August 2015, Volume 65 Issue 8 Pages 1165-1182

http://dx.doi.org/10.1007/s10236-015-0863-5

http://archimer.ifremer.fr/doc/00275/38631/

(C) Springer-Verlag Berlin Heidelberg 2015

\title{
Small-scale variability of the current in the Strait of Bonifacio
}

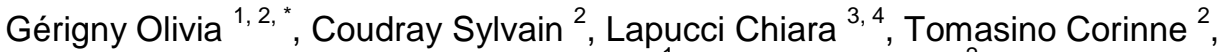 \\ Bisgambiglia Paul-Antoine ${ }^{1}$, Galgani Francois ${ }^{2}$
}

\author{
${ }^{1}$ Univ Cors Pasquale Paoli, CNRS UMR SPE 6134, UMS Stella Mare Lieu dit U CASONE 3514, F- \\ 20620 Biguglia, France. \\ 2 IFREMER, Dept Oceanog \& Dynam Ecosyst, Lab Environm Ressources Provence Azur Corse, RST \\ ODE LERPAC, F-33083507 La Seyne Sur Mer, France. \\ ${ }^{3}$ Natl Council Res IBIMET CNR, Inst BioMeteorol, I-50145 Florence, Italy. \\ ${ }^{4}$ Environm Modelling \& Monitoring Lab Sustainable D, I-50019 Florence, Italy. \\ * Corresponding author email address : gerigny@univ-corse.fr
}

\begin{abstract}
:
Current dynamics in the Strait of Bonifacio (south Corsica) were investigated at a small scale during the STELLAMARE1 multidisciplinary cruise in summer 2012, using in situ measurements and modeling data. The Strait of Bonifacio is a particularly sensitive marine area in which specific conservation measures have been taken to preserve the natural environment and wild species. Good knowledge of the hydrodynamics in this area is essential to optimize the Marine Protected Area's management rules. Therefore, we used a high-resolution model $(400 \mathrm{~m})$ based on the MARS3D code to investigate the main flux exchanges and to formulate certain hypotheses about the formation of possible eddy structures. The aim of the present paper is first to synthetize the results obtained by combining Acoustic Doppler Current Profiler data, hydrological parameters, Lagrangian drifter data, and satellite observations such as MODIS OC5 chlorophyll a data or Metop-A AVHRR Sea Surface Temperature (SST) data. These elements are then used to validate the presence of the mesoscale eddies simulated by the model and their recurrence outside the cruise period. To complete the analysis, the response of the 3D hydrodynamical model was evaluated under two opposing wind systems and certain biases were detected. Strong velocities up to $1 \mathrm{~m} \mathrm{~s}(-1)$ were recorded in the east part due to the Venturi effect; a complementary system of vortices governed by Coriolis effect and west wind was observed in the west part, and horizontal stratification in the central part has been identified under typical wind condition.
\end{abstract}

Keywords : ADCP profiles, Regional model, Hydrodynamic, Corsica current, Strait circulation, Northwest Mediterranean basin 


\section{Introduction}

Lying between Corsica and Sardinia islands, the Strait of Bonifacio (SoB) is of significant economic interest linked to many human activities: shipping routes with thousands of ships, sometimes carrying dangerous or pollutant materials, fishing and tourism (Sorgente et al. 2012). It is also an area with a strong ecological heritage due to the presence of numerous emblematic species and has thus been declared a "Particularly Sensitive Sea Area" (PSSA) (International Maritime Organization 2011). In 2012, an International Marine Park (PMIBB, http://www.oec.fr/) was created by merging two national reserves: the French marine reserve (RNBB, http://www.rnbb.fr/) and the Italian national reserve (Arichpelago of $\mathrm{La}$ Maddalena, Sardinia, http://www.lamaddalenapark.it). In this context, the environmental stakes involved are fundamental for preserving its biodiversity with both flora and fauna resources. Due to the richness of this area and the presence of PMIBB, many studies are currently being conducted in various fields (biology, pollution, population dynamics, etc). To maintain the ecological status of the site's coastal waters for future years, good knowledge of currents in the channels at local scale is required. Straits and channels in the Mediterranean Sea are key regions because they help to understand the role of water mass transport (inflow and outflow) from basin to basin (Béranger et al. 2005). Obtaining better understanding of the hydrodynamics in these areas is a complex task requiring that all the processes involved are taken into account.

The essential features of the hydrodynamic circulation in the North-Western Mediterranean Sea have been described and discussed in previous studies at large scales of space and time. The present state of knowledge about currents in the Thyrennian basin is described on figure 1, according to the previous studies (Iacono et al. 2013; Millot and Taupier-Letage 2005). This general circulation involves the main water mass named Atlantic Water (AW), entering through the Gibraltar Strait with colder characteristics, flowing along the North-African coast and gyrating around the Tyrrhenian basin. North Balearic Front, whose position varies seasonally, represents the northern limit of the Algerian Basin which acts for Atlantic Water reserve. When blowing on Corsica island, the northwest wind (named mistral) is channeled and accelerated by the orography in the Strait of Bonifacio, generating by divergence a cyclonic circulation, at very east of the Strait. Under the Coriolis effect, the flow tends to enter from west to east. The water balance between the two basins through the SoB was first studied by (Millot 1987). In addition, marks in the sediment on the sea-floor along the main path of the current have been identified by sonar imagery in the SoB (Pluquet 2006). To the authors' knowledge, there are as yet few studies describing the variability of the current around the SoB at a smaller scale of space and time: we can mention a study of oil spill dispersion forecasting system using a barotropic model as well as a short study in the middle of the Strait using moored instruments (Cucco et al. 2012; Gerigny et al. 2011b). To go further, it was then necessary to conduct a study in each compartment of the strait to investigate more precisely the local variability of the currents.

For this, an initial research program called MOMAR (Sistema integrato per il MOnitoraggio e il controllo dell'ambiente MARino, http://www.mo-mar.net/), was funded in 2009 by the European Inter-regional project INTERREGIV, to prepare the environmental monitoring of sensitive areas between Corsica, Sardinia and Tuscany. In this project, a numerical model of the coastal current has been built and validated. In 2012, at the end of the MOMAR program, IFREMER (Institut Français de Recherche pour l'Exploitation durable de la Mer), 
the UCPP (Université de Corse Pasquale Paoli) and CNRS (Centre National de Recherche Scientifique - UMR 6134) organized a measurement cruise named STELLAMARE1 in order to collect data on planktonic larvae, quantify the presence of micro-waste in water and study the hydrodynamics in the SoB. In this context, we first made use of our high resolution regional model named CORSE400m to identify the main hydrodynamic processes and localize the presence of the main eddy structures before the cruise. To confirm these hypotheses, we then made use of in-situ data: Acoustic Doppler Current Profiler (ADCP) and Conductivity Temperature Depth (CTD) across a grid covering the whole area. Using these measurement data as feedback, we were able to validate certain processes and obtain more precise information on water stratification. In parallel, satellite data such as MODIS OC5 chlorophyll $a$ data and Metop-A AVHRR Sea Surface Temperature (SST) data were taken into account to estimate the recurrence of the structures over longer periods. Finally, by launching Lagrangian SVP-Argos drifters during the cruise, it was possible to confirm with a good precision the location of these windinduced vortexes.

A description of the methods and data is given in section 2 of this paper. In the results and discussion, section 3, we first present an analysis of wind conditions after which we provide a comparison between the hydrological data with the model results. This is followed by an analysis of the ADCP profiles in conjunction with cross-sections of the model to study the current and hydrodynamics in the different compartments of the Strait. Then, we use additional data, namely satellite chlorophyll $a$, SST and drifters, to validate and support the results obtained. Finally, in this part, we discuss all the results and propose summaries on both the small scale variability of the current observed during a short period in the SoB and model reliability based on quantitative analysis. In section 4, we announce which hypotheses should be validated by the new measurements, as well as the usefulness of this work (including both the knowledge obtained and the model as a tool) for applications in various fields.

\section{Methods and data}

\subsection{Methodology used to conduct the sea cruise}

As mentioned previously, the STELLAMARE1 cruise was a multidisciplinary campaign and compromises were necessary to perform the physical, chemical and biological measurements. The CORSE400m model, validated at large scale in 2012 (http://www.mo-mar.net), was primarily used in forecast mode to identify potentially interesting mesoscale eddy structures. ADCP transects were then optimized to obtain vertical cross sections of these potential vortex structures and take water samples at the same time. After the cruise, the model was rerun with reanalyzed meteorological forcing variables and the simulation results were compared to measured data. After that, satellite images were used to make observations on the recurrence of the mesoscale structures throughout the summer period.

\subsection{Study area: The Strait of Bonifacio (SoB)}

The SoB is located in the North-Western Mediterranean Sea and separated into two distinct sub-basins: the Tyrrhenian Sea and the Ligurian-Provencal basin (Fig 1). Narrow in its middle (14 km large), the SoB covers 
80,000 ha (Mouillot et al. 2008) and is dotted with many islands and islets. Along the Corsican west coast, the continental shelf is relatively narrow with an average of $12 \mathrm{~km}$ between the $-20 \mathrm{~m}$ and $-100 \mathrm{~m}$ isobaths (Fig 2). On the opposite side, the Corsican east coast has a wider continental shelf and the $-100 \mathrm{~m}$ isobath is currently located $25 \mathrm{~km}$ off the coast. In the western section of the SoB, three bathymetric basins are clearly identified at the bottom. These small basins are indicated by circles and letters A, B and C (Fig 2). The east-west channel has an average depth of approximatively $70 \mathrm{~m}$. It is delimited on the east by small archipelagos (Lavezzi and La Maddalena) with shallow beds and on the west by the Moines Islets. The water depth in the eastern and western openings slowly increases down to 90-100 m before approaching the continental slope, where strong bathymetric gradients are observed (Cucco et al. 2012).

The SoB is a particularly windy region where winds blow 328 days a year (171 days with a wind $>16 \mathrm{~m}$ $\mathrm{S}^{-1}$ (Mouillot et al. 2008; Office de l'Environnement de la Corse 2007). This region of South Corsica is primarily dominated by westerly winds (about 50 percent throughout the year) blowing between $260^{\circ}$ and $300^{\circ}$, and with speeds generally higher than $8 \mathrm{~m} \mathrm{~s}^{-1}$ (called Libeccio). The second mode is represented by easterly winds (about 30 percent of the year) blowing during winter between $60^{\circ}$ and $100^{\circ}$, with speeds mostly ranging from 5 to $8 \mathrm{~m}$ $\mathrm{s}^{-1}$ (called Gregale). Water circulation is strongly regulated by this regime with often violent winds (only 2 percent are slower than $2 \mathrm{~m} \mathrm{~s}^{-1}$ ) generating very strong currents in the area (Gerigny et al. 2011b).

Seawater temperatures correspond to what is typically encountered in the north-western Mediterranean with winter temperature values not falling below $12^{\circ} \mathrm{C}$ and with average summer temperatures around $22^{\circ} \mathrm{C}$. Warmer values can occur in the surface layer $\left(24\right.$ to $\left.27^{\circ} \mathrm{C}\right)$ and tides have a very slight influence on current amplitude, with a maximum displacement of the water level of about $0.25 \mathrm{~m}$ (Gérigny 2010; Gerigny et al. 2011a). Salinity is relatively constant between 37.7 and 38.8, due to small freshwater input (Artale et al. 1994). The runoffs coming from rivers are low $(572 \mathrm{~mm} /$ year) which is characteristic of this western Mediterranean region (Cucco et al. 2012). Some studies have pointed out the existence of strong current intensities drained by a Venturi effect, particularly in the middle of the Strait of Bonifacio.

\subsection{Data acquisition at sea: ADCP, CTD and drifters}

Currents in the water column were measured throughout the SoB along a predefined grid, giving priority to north-south transects. For this paper, we selected five transects (P2, P4, P12, P14, P23, Fig 2) which gave the best acoustic images of the currents.

Two ADCP profilers were used for the STELLAMARE1 cruise. The first one, provided by IFREMER, was mounted on a towed fish alongside the ship at 2 meters depth to avoid boat movements and obtain more precise data. The configuration was designed for shallow waters with 100 vertical cells of 1 meter resolution in bottom-track mode and average processing of 30 seconds. The second one was provided onboard by the INSU (Institut National des Sciences de l'Univers, http://www.insu.cnrs-dir.fr/) and fixed on the hull of the OV-Tethys II ship. Its generic configuration was fixed at 60 vertical cells of 4 meters with a real-time averaging process run every minute and bottom tracking when possible (Leredde et al. 2007; Petrenko et al. 2005). The precision of both RDI $300 \mathrm{kHz}$ ADCP data is given at $0.02 \mathrm{~ms}^{-1}$. 
Towed ADCP data processing was performed in real-time by the RDI VmDas software and then treated offline with the RDI WinADCP software providing automatic data smoothing. Shipboard raw-data analysis was performed after the cruise by the INSU's Technical Division and the resulting data set is used in this paper to check and confirm the validity of the main current directions given by the towed ADCP.

Hydrological parameters (temperature and salinity) were measured with the CTD probe SeabirdSBE19-V2 (precision of $0.005^{\circ} \mathrm{C}$ for temperature and $0.0005 \mathrm{~S} / \mathrm{m}$ for conductivity) only four times: three stations near the coasts and one station more off-shore (Fig 2).

To complete these measurements and obtain Lagrangian trajectories, three drifters (SVP-GPS WoceArgo) were launched in each compartment of the SoB (middle, east and west). They were dimensioned to follow the currents 15 meters under the surface. Each drifter was composed of a surface buoy linked to a cylindrical drogue and equipped with an ARGOS beacon to transmit its location via the NOAA satellite (Poulain et al. 2012).

\subsection{Oceanic Modelling: MARS3D}

Modelling was performed using the MARS-3D code (3D hydrodynamic Model for Applications at Regional Scale) developed at IFREMER and described in detail by Lazure and Dumas (2008). This code is based on 3D primitive equations with a classical Boussinesq approximation and hydrostatic assumption. Both 2D barotrope and 3D barocline calculation modes were distinct and spatial discretization was done using a staggered "C" grid (Arakawa and Lamb 1977) with a vertical sigma-coordinates system. Hydrodynamic boundary conditions were given by the MARS3D-MENOR model covering the northwest Mediterranean sea (Andre et al. 2005); its horizontal resolution was about $1.2 \mathrm{~km}$ with 30 sigma layers (Rubio et al. 2009). Atmospheric forcing was obtained from an MM5 model (Mediterranean Acri-ST model, resolution $3 \mathrm{~km}$ ) with a recording frequency of 3 hours. The MENOR configuration was also used to study the variability of the Liguro-Provençal north current (Andre et al. 2009) and the associated cross-shelf exchanges (Andre et al. 2009). The downsized coastal model CORSE400m, nested in the previous one, was run before the STELLAMARE1 cruise in previsional mode and after the cruise for reanalysis. It offers a finer grid resolution of about 400 meters and covers the whole of Corsica region $\left(40.72^{\circ}-43.32^{\circ} \mathrm{N} ; 8.15^{\circ}-9.95^{\circ} \mathrm{E}\right)$ including the SoB until the Sardinian coast to the south. In this regional configuration, the vertical scheme was based on the Pacanovski \& Philander formulation (1981) and horizontal dissipation was based on the Smagorinsky formula with a mean coefficient of 0.2 for viscosity.

In this paper, the model results were first used to give a general view of the current dynamics at the surface during the cruise period. Water column currents have been then investigated along few ADCP profiles and the method chosen was to quantify the main currents by analysing the best matching cross-sections in a spatio-temporal window corresponding to model uncertainties.

\subsection{Chlorophyll $a$ data by MODIS OC5 algorithm and SST from Metop-A AVHRR}

Satellite-derived chlorophyll $a$ concentrations [CHL] were estimated by OC5, an empirical ocean color algorithm on MODIS AQUA data (http://modis.gsfc.nasa.gov/). The OC5 algorithm, provided by Ifremer (Gohin et al. 2002), was initially developed to give accurate [CHL] estimations on the Bay of Biscay and the English Channel oceanic and coastal areas. OC5, recently updated by data from the French Mediterranean area, presents intrinsic robustness for both oceanic and coastal waters when compared with other regional and global 
algorithms used in the Ligurian and North Tyrrhenian sea (Lapucci et al. 2012) and also in other seas such as the study area in July, August and September 2012, were acquired from the online OBPG Data Processing System. All images had a spatial resolution of about $1 \mathrm{~km}^{2}$ at nadir and had been corrected for atmospheric effects.

SST Metop-A AVHRR Level-2 files, processed by GHRSST, containing all or part of the study area in July, August and September 2012, were acquired from NOOA. All the images had a spatial resolution of about $1.1 \mathrm{~km}^{2}$ at nadir and were already corrected from the atmospheric effects.

Nineteen pairs of chlorophyll a and SST maps were selected, while those with complete or partial cloud coverage of the study area were eliminated, taking into consideration dust concentration (SKIRON/DUST model developed by the University of Athens, AM\&WFG, http://forecast.uoa.gr/dustindx.php), precipitable water (from ECMWF), and MODIS flags.

\section{Results}

\subsection{Wind in the SoB: cruise conditions and comparison of wind between MM5 and MétéoFrance} (MF) data

During the STELLAMARE1 cruise period, wind data were recorded by MétéoFrance (MF) at the Pertusato Semaphore $\left(41^{\circ} 22^{\prime} 25.25^{\prime \prime} \mathrm{N}\right.$ and $\left.9^{\circ} 10^{\prime} 42.33^{\prime \prime} \mathrm{E}\right)$ with a mean velocity of $5.7 \mathrm{~m} \mathrm{~s}^{-1}$ and a standard deviation of $2.6\left(\min =0.8 \mathrm{~m} \mathrm{~s}^{-1}\right.$ and $\left.\max =11.8 \mathrm{~m} \mathrm{~s}^{-1}, \mathrm{n}=168\right)$. Westerly wind corresponded to about $56 \%$ of the seven-day cruise and easterly wind about $35 \%$ (the major directions is this area being west and north-east). Several changes in wind direction were recorded: first the wind was established as westerly since 3 August, then turned east from 4 August to 6 August, and stabilized back to westerly until the end of the cruise.

The measured data (MF) were compared with the simulated wind data (MM5, Fig 3). Temporal variations of wind amplitude were quite well reproduced and followed the trend shown by the in-situ data. Before 6 August the dynamics of the simulated data were lower than those of the measures because of the smoothing performed by the meteorological model masking very local scale events. Directions for large amplitudes were thus better reproduced and the phase difference between the two sets of data on the first day can be explained by the low wind conditions in addition to a local perturbation near the measurement station on land. After 6 August the rest of the recording reproduced real conditions with quite good dynamics and the binary wind system characterizing this area was clearly visible in the simulated data throughout the period. In brief, on average the MM5 model matched the in-situ data quite well and can be considered realistic enough to be used for atmospheric forcing in our MARS3D ocean circulation model with a reasonable level of confidence.

\subsection{Comparison of hydrology CTD data with the model results}

During the STELLAMARE1 cruise, four CTD profiles were recorded and then compared with the simulated data. The resulting curve given by the model (full line) and CTD data (dotted lines) are compared for both temperature (Fig 4.a) and salinity (Fig 4.b). The bias between the two sets of data (measure - model) was then calculated and plotted for temperature (Fig 4.c) and salinity (Fig 4.d).

Regarding temperature in the water column, the model reproduced the variations recorded in-situ reasonably well. The values displayed corresponded to those usually encountered during the summer season in 
the northwestern Mediterranean sea, i.e. between $25^{\circ} \mathrm{C}$ and $27^{\circ} \mathrm{C}$ at the surface and about $14^{\circ} \mathrm{C}$ at the bottom. However, at this scale, the model had difficulties in reproducing the surface stratification, except for the CTD12 station located on the Sardinian coast but with a homogeneous layer less thick of few meters. In the deep layer, for the stations located around Corsica (CTD11, CTD13 and CTD14), the bias was varying from $1{ }^{\circ} \mathrm{C}$ to $2^{\circ} \mathrm{C}$. Finally, the intercomparison between the four stations showed that temperatures were better estimated along the coast than in the channel. In fact, a general underestimation of the heat flow at the air-sea interface induced by solar radiation has been noticed previously in our model (Faure et al. 2012). Despite this, for deeper layers, the model was able to give a representative temperature gradient. Regarding salinity, for all the measure points, the model curves were smoothed throughout the water column but the halocline was detected at about 15 meters even if less visible in the surface layer. In the second part of the curve, the model showed a consistent overestimation of salinity values with a constant average bias from 0.2 to 0.3 psu. This gap was already observed in the MENOR configuration used to force our model throughout the watercolumn at this time (Faure et al. 2012) and has been corrected after that in most recent version of the MENOR model.

For the three coastal stations located on the 50 meters isobath (CTD11, 12 and 13) we assume that the model can produce acceptable hydrological information at this scale, after systematic correction of the salinity bias. Due to its position along the continental slope where vortex activity was greater, the last station CTD14 located near the 100 meters isobath, presented a less significant simulated profile. Whatever the case, at this resolution, the model was declared good enough to represent the general dynamics of the Strait, essentially constrained by wind and bathymetry. Better modeling of the heat flow in the regional air-sea model may improve the slope of the curves and give a more homogeneous surface layer. In addition, by modifying the numeric vertical scheme we should be able to better estimate temperatures for the surface layer in this area.

\subsection{Current profile analysis}

To characterize the hydrodynamics observed in the SoB, a quantitative analysis of the main currents measured by ADCP has been done on the selected profiles and compared to model results. Then, for each compartment of the Strait (east, west and middle) and for different wind configurations, the orientation and amplitude of these local currents are described in details. All the data were used for this analysis: both ADCPs data set (shipboard one and a towed one), model results at the surface and in the water column (cross-sections), MODIS OC5 chlorophyll $a$ data, Metop-A AVHRR SST data and drifter trajectories. Initial analysis of the borders of the Strait (both east and west) helped to explain the origin of the incoming and outgoing flows.

\subsubsection{Quantitative analysis of the main currents}

The comparison between current's amplitude and directions measured by ADCP profiler and the corresponding cross-sections calculated by the model is presented in Table 1. The method used was first to determine vertical layers and horizontal sections in the ADCP data for each profile, to find the orientation of the most important currents. Comparison is made separately on $\mathrm{U}$ and $\mathrm{V}$ components to find the occurrence of these oriented currents in the simulation results by using a wide time window of 12 hours, considering the accumulation of uncertainties in both meteorological and hydrodynamical models. In a second time, the best matching profile was selected by using a spatial window of more or less $0.05^{\circ}$. 
The time gap in models results is of about 9 hours in the western part of the Strait, 3 hours in the middle

and 1 hour in the eastern part. This can be explained by an underestimated west wind in the meteorological forcing at the beginning of the cruise and by a lack of energy in the western boundary conditions supplied by the MENOR model, generating slower movements of the water masses.

For in-situ data, the mean and standard deviation were calculated on each selected current vein; aberrant values were rejected and a filter was applied to eliminate noisy data in first 10 meters under the surface and last 10 meters above the bottom. For model results, the average amplitude of the calculated current was obtained directly by tracking the best 400 meters cells in the same vertical/horizontal section.

In a first analysis, the orientation of the components are globally well calculated by the model for each profile, but the meridian component $(\mathrm{V})$ is better represented than the zonal component $(\mathrm{U})$. For each section, the most significant calculated velocities correspond approximatively to the average measured values with an acceptable error of less than $0.1 \mathrm{~m} \mathrm{~s}^{-1}$ except for the profile P14 in the middle of the Strait, where subsurface velocities are underestimated (less than 50\%) and canalized currents at the bottom are not represented. In fact, currents in the middle of the Strait are very instable due to the rapid changes in the wind direction at the surface and the presence in the water column of opposite currents entering and exciting of the Strait. The Corse 400 model is not able to calculate such a precise stratification at this scale and the west side of the Strait, where movements of the water masses are slower, is better represented.

\subsubsection{Venturi effect at the east of the strait}

In the east part of the Strait, a Venturi effect was observed when the wind blew from the west, as it did on 6 August 2012. It is clearly represented in the fields of currents calculated by the model for both the surface and bottom layers (Figs 5.a and 5.b). This effect corresponded to an increase of current velocity when the pressure decreased, creating an aspiration phenomenon resulting from the horizontal narrowing between the Sardinian and Corsican coasts and a vertical narrowing due to the higher level of the bathymetry in this area. The consecutive acceleration of the flux is evident on the measured ADCP profile as well as on the simulated profile, with a maximum current of $0.5 \mathrm{~m} \mathrm{~s}^{-1}$, oriented north and east throughout water column and a simulated current less important of about $0.3 \mathrm{~m} \mathrm{~s}^{-1}$ with generally the same orientation (left part of Figs 6.a and 6.b). The entire eastern part of the SoB was mainly driven by this process, typical of strait areas surrounded by hills or cliffs.

In the middle of the ADCP profile we observed an inverted current oriented north and west (Fig 6.a), with lower intensities at about $0.2 \mathrm{~m} \mathrm{~s}^{-1}$, and separated from the former by a small bank at the bottom. The corresponding simulated profile represents this compensation current oriented more westwards and shows slightly lower values (between 0.1 and $0.2 \mathrm{~m} \mathrm{~s}^{-1}$, Fig 6.b). A small third stratum oriented southwards appears at the end of the ADCP profile and corresponds to residual waters coming from the south part of the Corsica channel. This south current was well reproduced by the model at the bottom but also at the surface at the end of the simulated profile.

\subsubsection{Circulation in the western part of the strait.}

In the western part of the Strait, along the continental slope and under the Coriolis effect, there is a friction of the water masses along the Corsican coast. This phenomenon is reinforced when the wind is blowing from west at the surface. The model (Fig 7.a) calculated for 3 August clearly shows a system of two 
anticyclonic/cyclonic vortexes on the west boundary (named B and D), at longitude $8.60^{\circ}$. They are forced by a

\subsubsection{Water stratification in the middle of the strait}

In this transition area the situation is much more complex, and can vary according to the direction of the wind. Nevertheless, two linked main phenomena are well identified: first, in the middle of the water column, we can note the presence of a strong eastward current introducing water from the Provencal basin into the Tyrrhenian sea, reinforced when the wind blows from the west as it was between 2 and 4 August (Fig 9.a); and secondly, in compensation, a water flux entering at the bottom from the eastern Corsican coast and moving westwards, following the coastline, when the wind blows eastwards, as shown by the model after 4 August at $12 \mathrm{~h} 00$ (Fig 9.b).

Two ADCP profiles at two different longitudes were measured in the middle of the Strait during this changing configuration (wind turning from west to east) to characterize the water exchange. On the profile P12 (longitude $9.10^{\circ}$ west of Pertusato), taken from Corsica to Sardinia (i.e. north to south), the whole seabed was filled by a relatively slow moderate south-west current, with a maximum velocity of $0.2 \mathrm{~m} \mathrm{~s}^{-1}$ (Fig 10.a). In the middle, in the deep layer between 20 and 40 meters, we observed a north-west current only $3 \mathrm{~km}$ wide, but twice as strong, entering the Strait from the east with an average velocity of $0.4 \mathrm{~m} \mathrm{~s}^{-1}$ (Fig 10.a). The whole center of the surface layer was spread by the north-east current coming from the west. On the profile P14 (longitude $9.15^{\circ}$, east of Pertusato), this time taken from Sardinia to Corsica (i.e. south to north), the stratification was more complex horizontally and vertically both. During the first 3 kilometers, we observed a fairly weak north-west current in the surface layer with a velocity less than $0.2 \mathrm{~m} \mathrm{~s}^{-1}$ (Fig 11.a) entering the Strait along the Italian coastline. After 3 kilometers, in the deep layer, the orientation of the inverted current was south-east, with a 
slightly stronger velocity of about $0.3 \mathrm{~m} \mathrm{~s}^{-1}$, corresponding to the flux exiting the Strait and moving toward the

\subsubsection{Téthys ADCP data}

As announced in the paragraph on the methodology (part 2.1), we made use of the shipboard ADCP dataset to give a more synthetic view of the current for the whole area and confirm the results of the towed ADCP profiles. Despite the fact that the vertical fixed configuration was poorer in precision for the small depths, we were able to use this second dataset to draw field currents along the ship path for 3 layers: subsurface layer (Fig 12.a), middle layer (Fig 12.b) and bottom layer (Fig 12.c). When comparing them, we observed that the water column in the west compartment along the continental slope (isobaths $50 \mathrm{~m}$ ) was oriented northwest and very homogeneous down to the bottom, confirming the towed ADCP profile P2 (Fig 8). Conversely, the water column in the middle compartment (underlined with red boxes, Fig 12) was clearly stratified, with the same westward current, but confined in the deep layer along the Italian coast. There was also a strong eastward current exiting from the Strait of Bonifacio at the bottom, as already shown by the towed ADCP profile P14 (Fig 11). Finally, the current near the Corsican coast (isobath $20 \mathrm{~m}$ ) was also exiting from the Strait. However, it occupied the entire water column. The amplitude and direction currents given by the Tethys' ADCP are consistent with the data provided by the towed ADCP. So, the instrument does not introduce additional bias and we can consider that the data obtained are reliable.

\subsection{Process validation by drifter trajectories}

Three drifters were launched to characterize the dynamics of the main vortex activities along the Corsican coasts (Fig 13). The first drifter launched in the south part of the Strait near the geostrophic flux clearly shows the cyclonic-anticyclonic system (B and D) previously identified along the continental slope with both ADCP measurements and model results. Then it was drawn by a very local current along the shore before entering the Strait, and driven by the small vortex (A) near Bonifacio. The second drifter, launched in the west part of the channel, was carried by the northwest current before returning to the SoB, where it was trapped in an anticyclonic (D) structure. Its position thus exactly overlapped the center of the vortex simulated by the MARS3D model. The path of the third and last drifter, launched in the east compartment of the Strait, shows a small vortex (named E) directly linked to the Venturi effect along the east coast. It is also visible on the MARS3D-CORSE400m simulations discussed previously (in part 3.3.2, Figs 5.a and 5.b). It was then driven by the classical main circulation until the Tyrrhenian basin. After observing these drifters for a period of 20 days, 
we were able to validate the existence of the four mesoscale structures suggested by the model over a longer period.

\subsection{Identification of the model hydrodynamic structures by satellite data: chlorophyll-a and SST}

Mesoscale eddies can be observed from satellites, either via SST or by biogeochemical parameters such as chlorophyll a. In fact, under certain conditions, the color of the sea (ocean color) provides an estimate of the typical mesoscale motion that can be clearly observed from space, as well as information on biological activity by the detection of algal blooms (Robinson 2010). In the Western Mediterranean area, summer is the most oligotrophic period of the year, when it is easy to detect relatively low concentrations of chlorophyll $a$ that can clearly trace the dynamics of surface structures as they are easily detectable against a background of very low chlorophyll $a$ values. The satellite OC5 [CHL] range in August in this area is $0.10-0.21 \mathrm{mg} / \mathrm{m}^{3}$, but it should be noted that OC5 chlorophyll $a$ algorithm does not retrieve values lower than 0.1 for chlorophyll $a$.

The first step in hydrodynamic structure identification by satellite data was to compare the MODIS OC5 chlorophyll $a$ and Metop-A AVHRR SST maps with the current maps obtained by the MARS3D-CORSE400m model during the days of the STELLAMARE1 cruise. The second step was to extend those observations to July, August and September 2012. As expected, SST data showed quite homogeneous values for that time of the year, so they were used as additional information to structure detection on chlorophyll $a$ maps. Mesoscale eddies can be identified on the satellite images by an increase of the chlorophyll $a$ surface concentration, shown in the maps as a spot of green color in contrast to the surrounding blue water (corresponding to the lowest chlorophyll $a$ values). It is important to note that under the summer oligotrophic conditions it is difficult to detect a decrease in chlorophyll concentration that can trace as well the presence of an eddy. 19 matchups were found (Table 2), this low number was of course strongly affected by the need to analyze satellite images almost completely free of cloud cover.

Of the 19 matchups found, 15 showed agreement between the satellite maps and those coming from hydrodynamic model: examples are shown on Fig 14 a, b, c, where surface structures are pointed out with circles. 5 of the satellite-model matchups detected a double system structure (Fig 14 a), composed by the B and D structures previously described (Paragraph 3.3.3 and Fig 7).

The double structure (B and D) and the eddy C could be clearly identified on satellite maps of July (Fig 14.a), both for chlorophyll $a$ and SST parameters, the latter map showing an upwelling along the west coast Corsica. In August (Fig 14.b), chlorophyll $a$ satellite data only shows B structure, when compared to the model, while the SST map shows the presence of another structure (F) on the Italian side; this is going to be analyzed in further studies. In September (Fig 14.c), under a strong east wind, the system of structures A, B, C, D are destroyed by a strong flux of water coming from the East and generating the structure $\mathrm{A}^{\prime}$, at the same position of the A structure but inverted.

We compared then data from the MM5 wind model with the selected satellite date and surface currents given by the model. This comparison confirm the existence of the mesoscale eddy structures in the western part of the SoB, and in some cases the existence of a double system structure, when strong wind is blowing from west in the SoB. 


\section{Discussion}

\subsection{Circulation summary}

The objective of this paper was to improve our knowledge about small scale hydrodynamics in the SoB by interpreting measured data and model simulation on a short period representative of a caracteristic wind transition. We obtained a general overview of the variability with a spatial repartition from west to east (Fig 15). In the west part, a system of complementary eddies (anticyclonic B and cyclonic D) was identified by the model and confirmed by drifters as well as satellite data over longer periods. The main structure B was more persistent and present until the bottom, with a diameter at the surface of about 20 kilometers. The recurrent nature of this structure B was also confirmed by a statistical study of marine litter concentrations in the SoB (Arcangeli et al. 2014) which shows that the highest concentration was located approximately in the center of the same mesoscale eddy. Already identified in several studies as Western Corsican Current (Astraldi and Gasparini 1992), the circulation at west creates an accumulation of waters along the slope which tends, under the Coriolis effect to be evacuated along the meridional Corsican coast towards the east. We can hypothesise that the flow of eddy B impacts against the bedrock formed by the vertical narrowing of the bathymetry and is amplified by the flow passing in the Tyrrhenian Sea, influencing the secondary vortex C. Using the model, we were able to further analyze the positions of these different structures. However, these interpretations will require new records to back them up. Further east, after the Lavezzi and Maddalena islands, the SoB is characterized by a Venturi effect, causing an acceleration of the outgoing flow until the Tyrrhenian Sea. The interaction with the southern current in Tyrrhenian basin, under appropriate wind conditions, generates a secondary vortex E along the oriental coast of Corsica.

This is the first time that the flows exchanged between the Tyrrhenian and Ligurian-Provencal basins have been mesured at such a local scale and throughout the water column after performing almost complete ADCP transects between Corsica and Sardinia. These first results indicate that the system is unsteady at the surface, but with a more consistent pattern just in the deep layer. Effectively, although the surface layer depends on the strong winds blowing east or west, a more stable current exists in the sub-surface, oriented from west to east, thus forming the main outgoing flux, further channeled at the bottom into two branches around the Lavezzi islands. In the deep layer, an inverted current flows from the south-east and enters the Strait heading north-west, thus creating a compensation flux, crossing the previous one and flowing along the Corsican coast until the Moines islets. However, this flow diagram cannot be taken for granted permanently in this part of the SoB. Indeed, the profiles in the middle of the Strait were recorded under low westerly wind velocities (August 4) with wind conditions not yet completely established. Since the currents in the Strait are strongly linked to winds (Cucco et al. 2012), the Venturi effect would certainly be amplified by a well-established westerly wind. Conversely, the contributions of the Tyrrhenian basin would probably be more considerable with a wellestablished easterly wind. However, in this study the main flow was clearly identified by the current measurements and the model showed that this flow tended to flow outwards to the east in the Tyrrhenian basin and join the geostrophic current. Based on these results, and through the accumulation of simulated data, new scenari could be hypothesize in the next future about wind-driven effects for both basins over longer periods, as well as on the origin of the vortex (regional circulation, obstacles, wind). In a further study, reusing annual simulation databases coupled with another marine mission based on moored instruments and the use of an 
autonomous Waveglider vehicle equipped with an ADCP, CTD and fluorimeter, will lead to a more detailed interpretation of the phenomena identified for the first time in this paper.

\subsection{Model reliability}

The atmospheric model MM5 used at this period lacks of energy, but reproduced the phenomena observed correctly and allowed to force the oceanic model with a good level of confidence.

In general, the oceanic model MARS3D-CORSE400m provided a range of relatively consistent estimations of the hydrological parameters, except for the systematic salinity bias of about 0.3 psu. This bias will be corrected by providing a new version of the MENOR model on the boundary conditions. Regarding the temperature, the bias observed under $15 \mathrm{~m}$ is about $+/-2^{\circ} \mathrm{C}$ and will be considered acceptable taking into account the resolution of model. The break steepening of the temperature curve over $15 \mathrm{~m}$ could be corrected by better modeling of the air-sea heat exchange induced by sunlight, while a new vertical scheme could be implemented by an AGRIF nested model for example. On average, the model underestimates the current's amplitude of about $0.1 \mathrm{~m} \mathrm{~s}^{-1}$. Despite this bias, the simulations were able to represent correctly centered structures, as demonstrated by lagrangian drifters and chlorophyll a observations with a space/time shift less than $1 / 10^{\circ}$ and a delay of few hours as explain in part 3.3.1. The spatial gap is less visible at the bottom and is inherent to this kind of regional model (Andre et al. 2009). The time shift does not seem linked to tide effects because their influence is not significant as cited in the part 2.2. New versions of the MENOR model should reduce this time shift by providing better adjusted boundary conditions, and this work is planned for the coming year. The MARS3DCORSE400m model was thus declared sufficient for this first interpretation of the small-scale variability in the SoB, and could further be used for statistical estimations of seasonal variations. Future studies, aimed at answering the specific needs of the marine park, could use a higher resolution model (100 or 200 meters) forced by this CORSE400m model and centered on the coastal region.

\subsection{Model validation with drifters and satellite data - Chlorophyll a and SST}

The use of drifters to detect surface structures gaves interesting results because of the very good agreement between the structures previously detected by the MARS3D-CORSE400m model and the ones observed and confirmed by the ADCP data. In addtion, satellite data can also be a powerful tool for tracking mesoscale structures. For this, physical parameter SST (Metop-A AVHRR) was observed together with the biological parameter chlorophyll $a$ (MODIS OC5). Although cloud cover caused the elimination of a large number of satellite images, good matching between satellite maps and hydrodynamic model results was found for the sunny days. On the basis of these encouraging results, the study of the hydrodynamics in the SoB could be extended by using regional model simulations over a larger number of years. This work should be conducted in parallel with satellite images possibly coupled with small-scale in-situ observations realized by autonomous vehicles such as gliders in the water column or wave-glider at the surface.

\section{Conclusion:}

The study we developed here is part of a longer-term research program aimed at analyzing the hydrodynamics of an important economic area and prepares other studies directly linked to the Natural Park's activities. The study was based on a high resolution regional hydrodynamic model that was validated in the south Corsica zone. This 
model allowed us to make a better interpretation of observed and assumed phenomena in the Strait of Bonifacio, involving high intensity currents sometime up to one meter/second. Working with complementary measures such as chlorophyll $a$ provides more consistency to the results obtained, particularly regarding (i) the presence of a set of complementary mesoscale structures in the west part of the Strait; (ii) the existence of a strong Venturi effect in the east and its interactions with neighboring water masses; (iii) the identification of the main exchange between both oceanic basins taking the form of intersecting fluxes in the water column. The hydrodynamic study of the SoB is only the first stage of more applied research work on larvae dispersal and the "connectivity" between the various protected areas of the Marine Park and dedicated to environmental and biological studies targeting priority zones. They will probably require the implementation of hydrodynamic zooms with finer resolutions, nested in the existing simulations and coupled with specific ecological models.

\section{Acknowledgements}

We thank MeteoFrance and INSU for providing the in-situ measures and ship-mounted ADCP data, as well as all the crew of the R/V Tethys II for their valuable support. This work was performed in the framework of cooperation between IFREMER, the LaMMA Consortium and the University of Corsica (UMS 3514 Stella Mare). It was funded by Interreg IV Project MOMAR/SICOMAR and CPER contract of Corsica (CTC/DRRT). We also thank David Le Berre for his technical assistance during the sea cruise. 
Andre G, Garreau P, Fraunie P (2009) Mesoscale slope current variability in the Gulf of Lions. Interpretation of in-situ measurements using a three-dimensional model Continental Shelf Research 29:407-423 doi:10.1016/j.csr.2008.10.004

Andre G, Garreau P, Garnier V, Fraunie P (2005) Modelled variability of the sea surface circulation in the North-western Mediterranean Sea and in the Gulf of Lions Ocean Dynamics 55:294-308 doi:10.1007/s10236-005-0013-6

Arakawa A, Lamb VR (1977) Computational design of the basic dynamical processes of the UCLA general circulation model. General circulation models of the atmosphere. In: General circulation models of the atmosphere. (A78-10662 01-47) New York, Academic Press, Inc., 1977 edn.,

Arcangeli A et al. (2014) Floating plastic: a monitoring model in the Western Mediterranean Sea Region. Density, composition and impact on the biota. Paper presented at the Workshop Rifiuti marini (Marine Litter). Una minaccia per gli ecosistemi marini e costieri. Corso teorico-pratico per la gestione sostenibile del detrito antropogenico sulle spiagge, Roma-Università degli studi Roma 3,

Artale V, Astraldi M, Buffoni G, Gasparini GP (1994) Seasonal variability of gyre-scale circulation in the northern Tyrrhenian Sea Journal of Geophysical Research 99 doi:10.1029/94JC00284

Astraldi M, Gasparini GP (1992) The seasonal characteristics of the circulation in the north mediterranean basin and their relationship with the atmospheric-climatic conditions J Geophys Res-Oceans 97:9531-9540 doi: $10.1029 / 92 \mathrm{jc} 00114$

Béranger K, Mortier L, Crépon M (2005) Seasonal variability of water transport through the Straits of Gibraltar, Sicily and Corsica, derived from a high-resolution model of the Mediterranean circulation Progress in Oceanography 66:341-364 doi:10.1016/j.pocean.2004.07.013

Cucco A et al. (2012) A high-resolution real-time forecasting system for predicting the fate of oil spills in the Strait of Bonifacio (western Mediterranean Sea) Marine Pollution Bulletin 64:1186-1200 doi:10.1016/j.marpolbul.2012.03.019

Faure V, Gatti J, Bensoussan N (2012) Analyse de la campagne MELBA et évaluation du modèle CORSE 400 m. Rapport Final.

Gérigny O (2010) Hydrologie et hydrodynamisme dans les bouches de Bonifacio : mesures in-situ, modélisation, influence sur la biomasse. Biologie des population et écologie, spécialiité océanographie, Université de Corse - Pascal Paoli

Gerigny O, Di Martino B, Romano J-C, Ulses C (2011a) A one-year (2005) comparison of seawater temperature series between in situ and modelling data: Application to the Strait of Bonifacio (South Corsica) Comptes Rendus Geoscience 343:278-283 doi:10.1016/j.crte.2011.01.002

Gerigny O, Di Martino B, Romano JC (2011b) The current dynamics inside the Strait of Bonifacio: Impact of the wind effect in a little coastal strait Continental Shelf Research 31:1-8 doi:10.1016/j.csr.2010.11.005

Gohin F, Druon JN, Lampert L (2002) A five channel chlorophyll concentration algorithm applied to SeaWiFS data processed by SeaDAS in coastal waters International Journal of Remote Sensing 23:1639-1661 doi:10.1080/01431160110071879

Iacono R, Napolitano E, Marullo S, Artale V, Vetrano A (2013) Seasonal Variability of the Tyrrhenian Sea Surface Geostrophic Circulation as Assessed by Altimeter Data Journal of Physical Oceanography 43:1710-1732 doi:10.1175/JPO-D-12-0112.1

International Maritime Organization (2011) Designation of the Strait of Bonifacio as a particularly sensitive sea area. Resolution MEPC.204 (62), annexe 22

Lapucci C et al. (2012) Evaluation of empirical and semi-analytical chlorophyll algorithms in the Ligurian and North Tyrrhenian Seas Journal of Applied Remote Sensing 6:063565-063561 doi:10.1117/1.JRS.6.063565

Lazure P, Dumas F (2008) An external-internal mode coupling for a 3D hydrodynamical model for applications at regional scale (MARS) Advances in Water Resources 31:233-250 doi:10.1016/j.advwatres.2007.06.010

Leredde Y, Denamiel C, Brambilla E, Lauer-Leredde C, Bouchette F, Marsaleix P (2007) Hydrodynamics in the gulf of Aigues-Mortes, NW Mediterranean sea: In situ and modelling data Continental Shelf Research 27:2389-2406 doi:10.1016/j.csr.2007.06.006

Millot C (1987) Circulation in the western Mediterranean-Sea Oceanologica Acta 10:143-149

Millot C, Taupier-Letage I (2005) Circulation in the Mediterranean sea The Handbook of Environmental Chemistry Series k:29-66 doi:10.1007/b107143. 
Mouillot D, Culioli JM, Pelletier D, Tomasini JA (2008) Do we protect biological originality in protected areas? A new index and an application to the Bonifacio Strait Natural Reserve Biological Conservation 141:1569-1580 doi:10.1016/j.biocon.2008.04.002

Office de l'Environnement de la Corse (2007) Plan de gestion de la Reserve naturelle des Bouches de Bonifacio, 2007-2011.

Petrenko A, Leredde Y, Marsaleix P (2005) Circulation in a stratified and wind-forced Gulf of Lions, NW Mediterranean Sea: in situ and modeling data Continental Shelf Research 25:7-27 doi:10.1016/j.csr.2004.09.004

Pluquet (2006) Recent evolution and sedimentation of the Corsican continental shelves. University of Corsica Pasquale Paoli

Poulain PM, Menna M, Mauri E (2012) Surface Geostrophic Circulation of the Mediterranean Sea Derived from Drifter and Satellite Altimeter Data Journal of Physical Oceanography 42:973-990 doi:10.1175/jpo-d$11-0159.1$

Robinson IS (2010) Discovering the Ocean from Space. In: Springer (ed). pp 78-80

Rubio A, Taillandier V, Garreau P (2009) Reconstruction of the Mediterranean northern current variability and associated cross-shelf transport in the Gulf of Lions from satellite-tracked drifters and model outputs Journal of Marine Systems 78:S63-S78 doi:10.1016/j.jmarsys.2009.01.011

Sorgente B et al. (2012) Effects of protection rules and measures in an important international strait area: the Bonifacio Strait JOURNAL OF OPERATIONAL OCEANOGRAPHY 5:35-44

Tilstone GH, Angel-Benavides IM, Pradhan Y, Shutler JD, Groom S, Sathyendranath S (2011) An assessment of chlorophyll-a algorithms available for SeaWiFS in coastal and open areas of the Bay of Bengal and Arabian Sea Remote Sensing of Environment 115:2277-2291 doi:10.1016/j.rse.2011.04.028 


\section{Figure captions:}

Fig 1 Circulation around Corsica from Gérigny, et al, 2011; Millot, 1987, Millot and taupier-Letage, 2005

Fig 2 Map of the SoB in the Western Mediterranean Sea, between Corisca and Sardinia, with ADCP transects and CTD stations. Three main basins (A, B, C) are identified in the bathymetry. They correspond to the location of hypothetical vortex activities provided by the model before the cruise

Fig 3 Comparison of wind amplitude $(\mathrm{m} / \mathrm{s})$ and direction $\left(^{\circ}\right)$ between in-situ data MétéoFrance (MF) in black and modelling data (MM5) in gray

Fig 4 CTD measurements and model results for (a) temperature and (b) salinity; bias of (c) temperature and (d) salinity between the measurement and model results. A negative bias corresponds to an overestimation of the data by the model and conversely, a positive bias corresponds to an underestimation

Fig 5 Surface (a) and bottom (b) current fields given by the MARS3D-CORSE model at a resolution of 400 meters. Intensity is of about $0.5 \mathrm{~m} \mathrm{~s}^{-1}$ few miles north of the isles (Venturi effect). The blue dash line represents the initial ADCP profiles P23 and the blue plain line the best matching model cross-section

Fig 6 (a) ADCP profiles measured at the end of the SoB between the Maddalena and Lavezzi islands, at longitude $9.30^{\circ}$ E. (b) Simulated profiles given by the MARS3D-CORSE model at a resolution of 400 meters

Fig 7 Surface current field given by the MARS3D-CORSE model, at a resolution of 400 meters. The mean intensity of the vortex is about $0.4 \mathrm{~m} / \mathrm{s}$. (a) for 3 August 2012 at 18:00; (b) 9 hours later. The vertical transect corresponding to the ADCP profile is indicated in blue (dash-line represents the initial longitude of the ADCP profiles P2-P4, plain-line represents simulated profile). Eddies are shown schematically by a circle and identified by a letter

Fig 8 (a) ADCP profiles recorded along the P2 and P4 transects at longitude $9^{\circ} \mathrm{E}$, with a vertical resolution of 3 meters, between the Moines islets and the Italian maritime border. (b) Simulated cross-section given by the MARS3D-CORSE model at longitude $9^{\circ} \mathrm{E}$ on 30 vertical levels

Fig 9 Surface current fields given by the MARS3D-CORSE model, resolution 400 meters, (a) in the sub-surface (b) at the bottom. The selected ADCP transect is indicated by a blue

Fig $10 \mathrm{ADCP}$ (a) and simulated (b) profiles along the P12 transect (west of Pertusato) at longitude $9.10^{\circ} \mathrm{E}$ with a vertical resolution of 1 meter, between the Moines islets and the Italian maritime border. ( 1 ping = 3 meters)

Fig 11 ADCP (a) and simulated (b) profiles along the P14 transect (east of Pertusato) at longitude $9.20^{\circ} \mathrm{E}$ with a vertical resolution of 1 meter, between the Moines islets and the Italian maritime border. ( 1 ping $=3$ meters)

Fig 12 Current profile recorded by the hull-mounted ADCP of Téthys II - INSU for the 3 and 4 August 2012. (a) $8 \mathrm{~m}$, (b) $16 \mathrm{~m}$, (c) $36 \mathrm{~m}$ depth. In red, stratification of the water column output, eastern Strait

Fig 13 Map of the drifter trajectories where eddy structures are represented by circles

Fig 14 Comparison for (a) 31 July 2012, (b) 9 August 2012, and (c) 16 September 2012 between (1) MODIS OC5 chlorophyll a, (2) Metop-A AVHRR SST and (3) MARS3D-CORSE400m model maps 
Fig 15 Summary map of small-scale variability of the current in the strait of Bonifacio during STELLAMARE1 cruise 


\section{Table captions}

1

2

Table 1 Comparison between measured and simulated data for Zonal (U) and Meridional (V) components. For each profile, the calculated mean on measured data for the specific water layer are compared with the most representative value of the simulated main current vein

Table 2 Comparison between chlorophyll $a$, SST, surface current model and wind data from the model in July, August and September 2012 
Click here to download Manuscript: fig 1.ti

Click here to view linked References

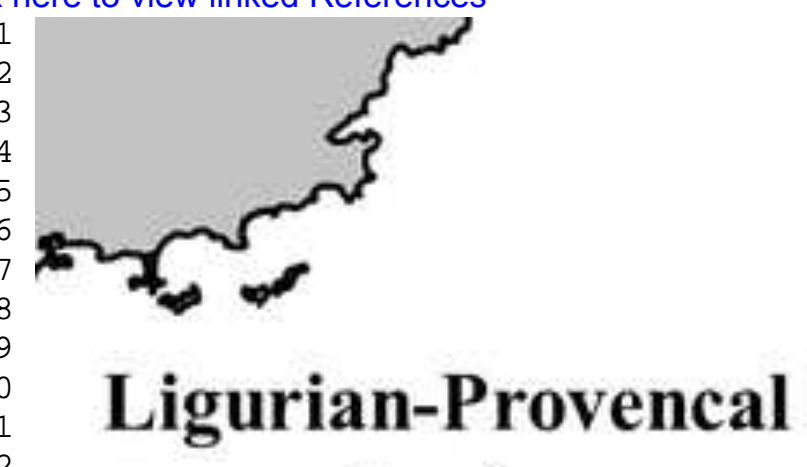

basin

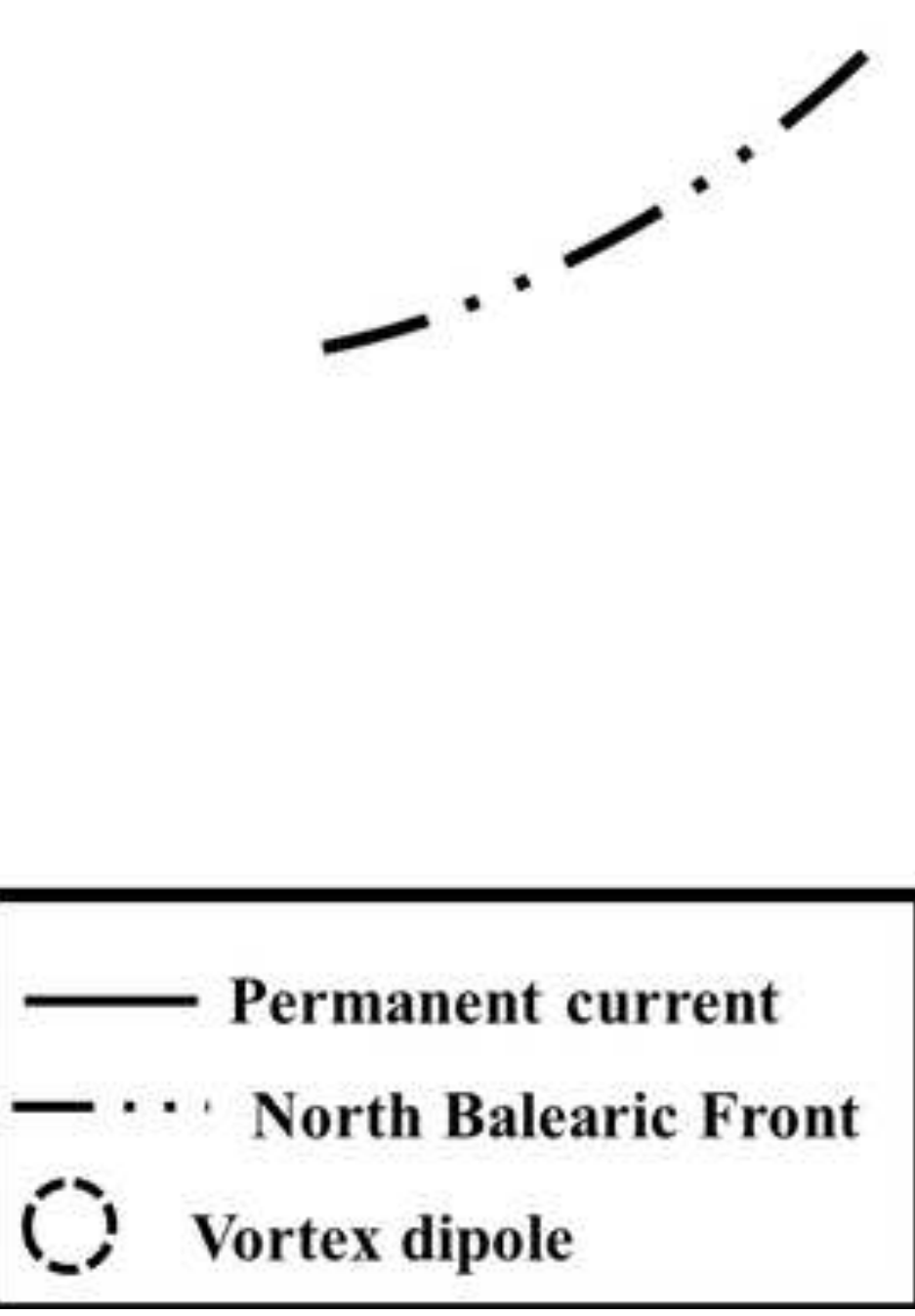

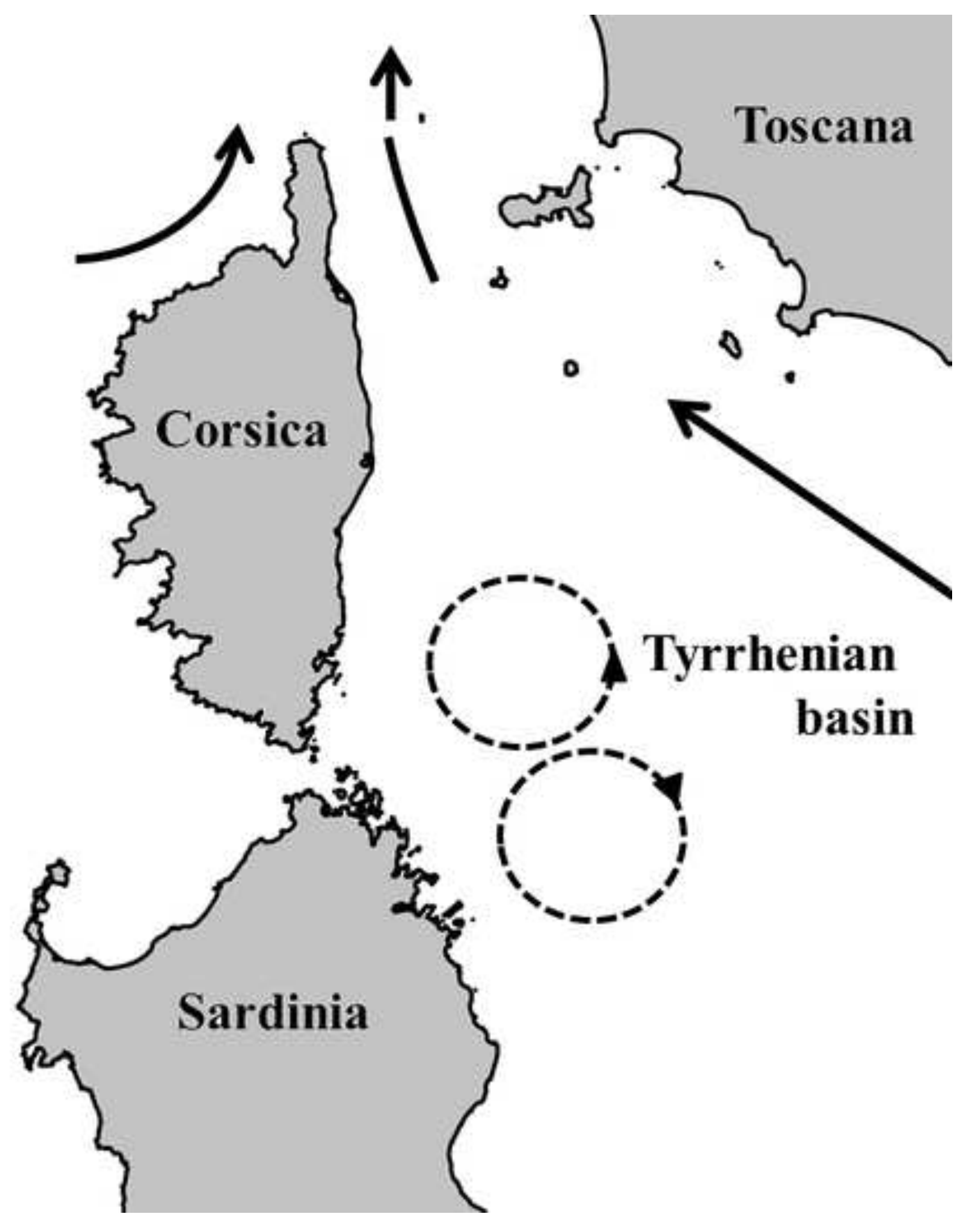


Click here to download Manuscript: fig_3_vent_MF_MM5.tif Click here to view linked References
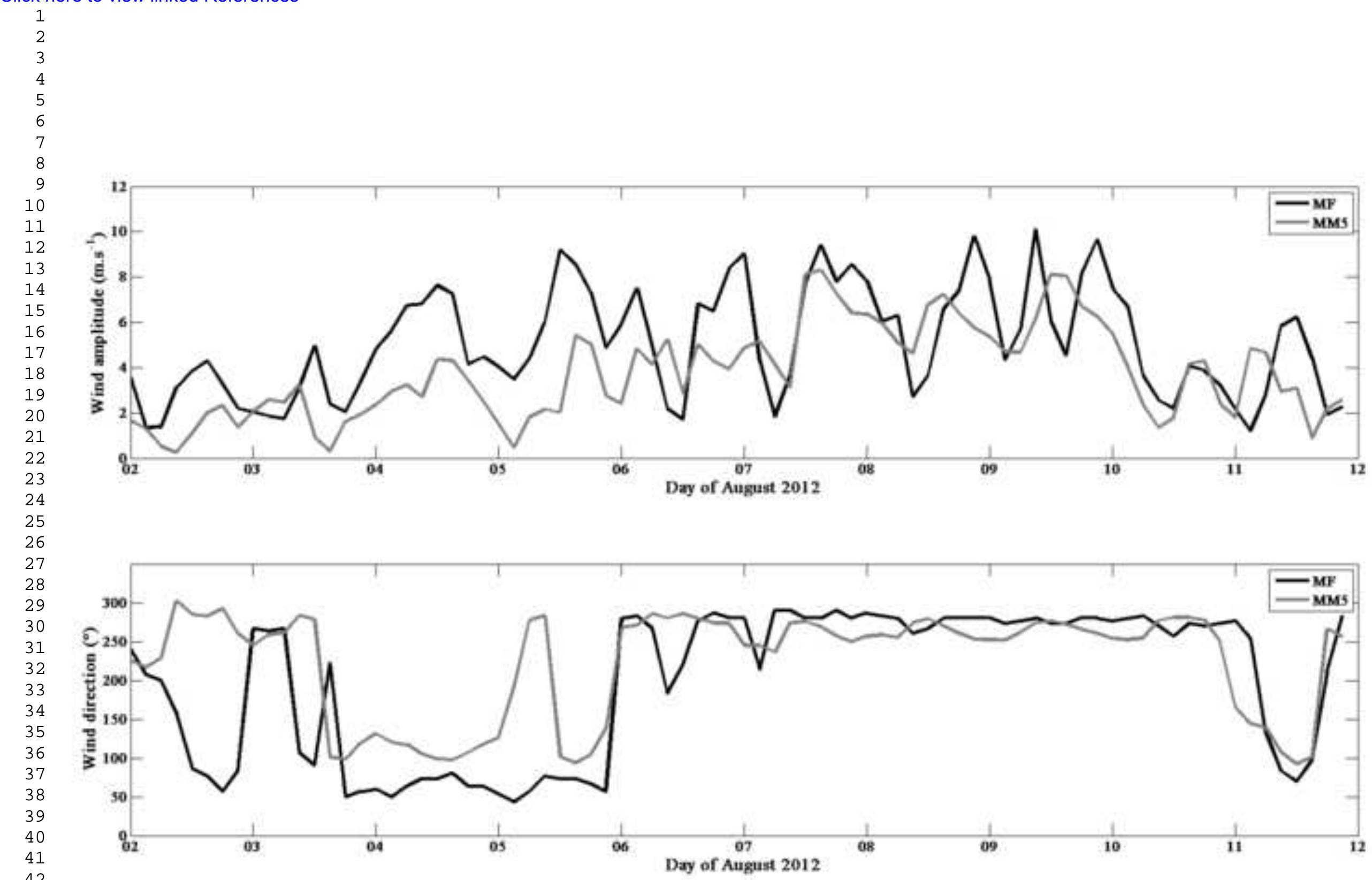

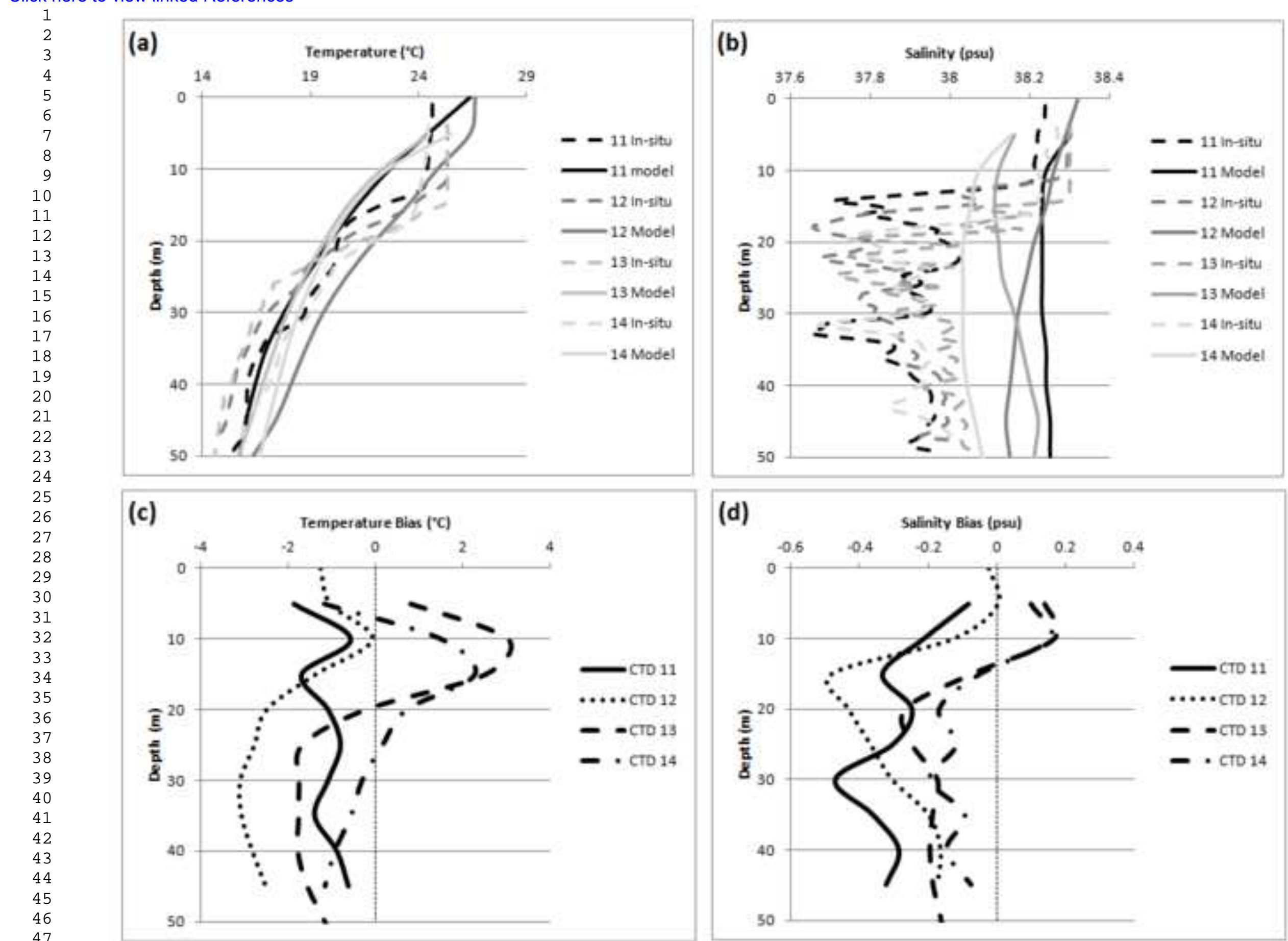

(d) 
figure_5

Click here to download Manuscript: fig_5_model_venturi_vrs3.TIF Click here to view linked References

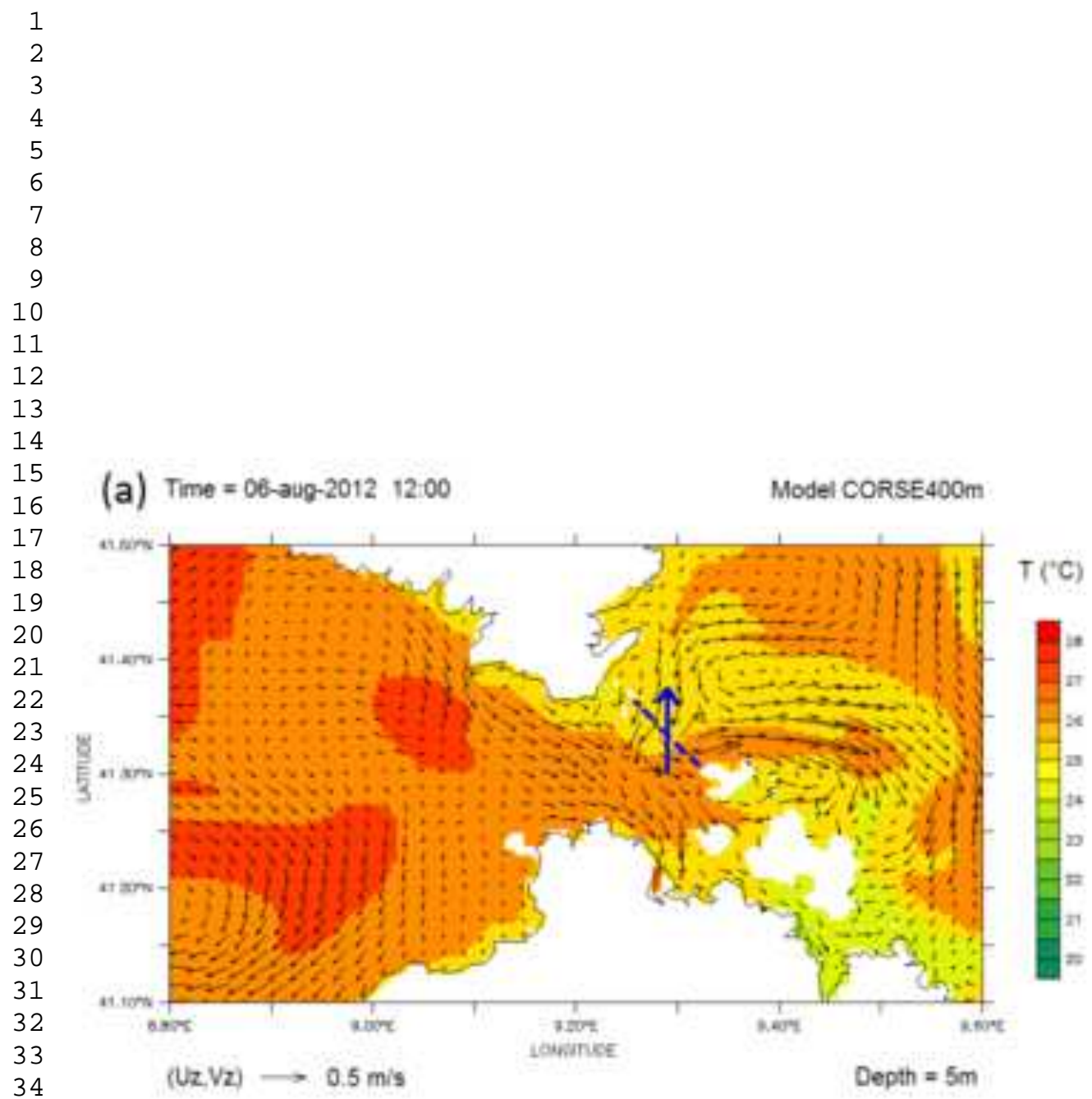

(b) Time $=0$-aug-2012 $\quad 12,00$

Model CORSE $400 \mathrm{~m}$

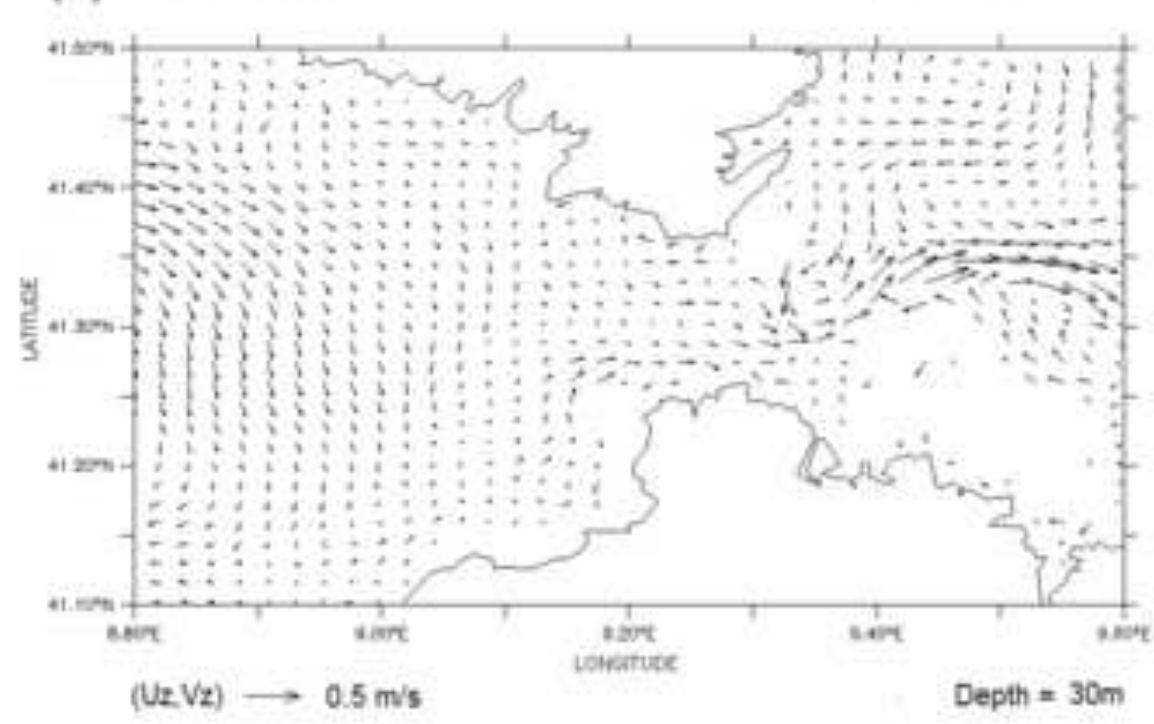

35

36

37

38

39

40

41

42

43

45

46

47 
Click here to download Manuscript: Fig_6a_vrs6.TIF

Click here to view linked References

(a) Time 06-aug-2012 11:00

ADCP Profile 23 - Longitude $=9.30^{\circ}$
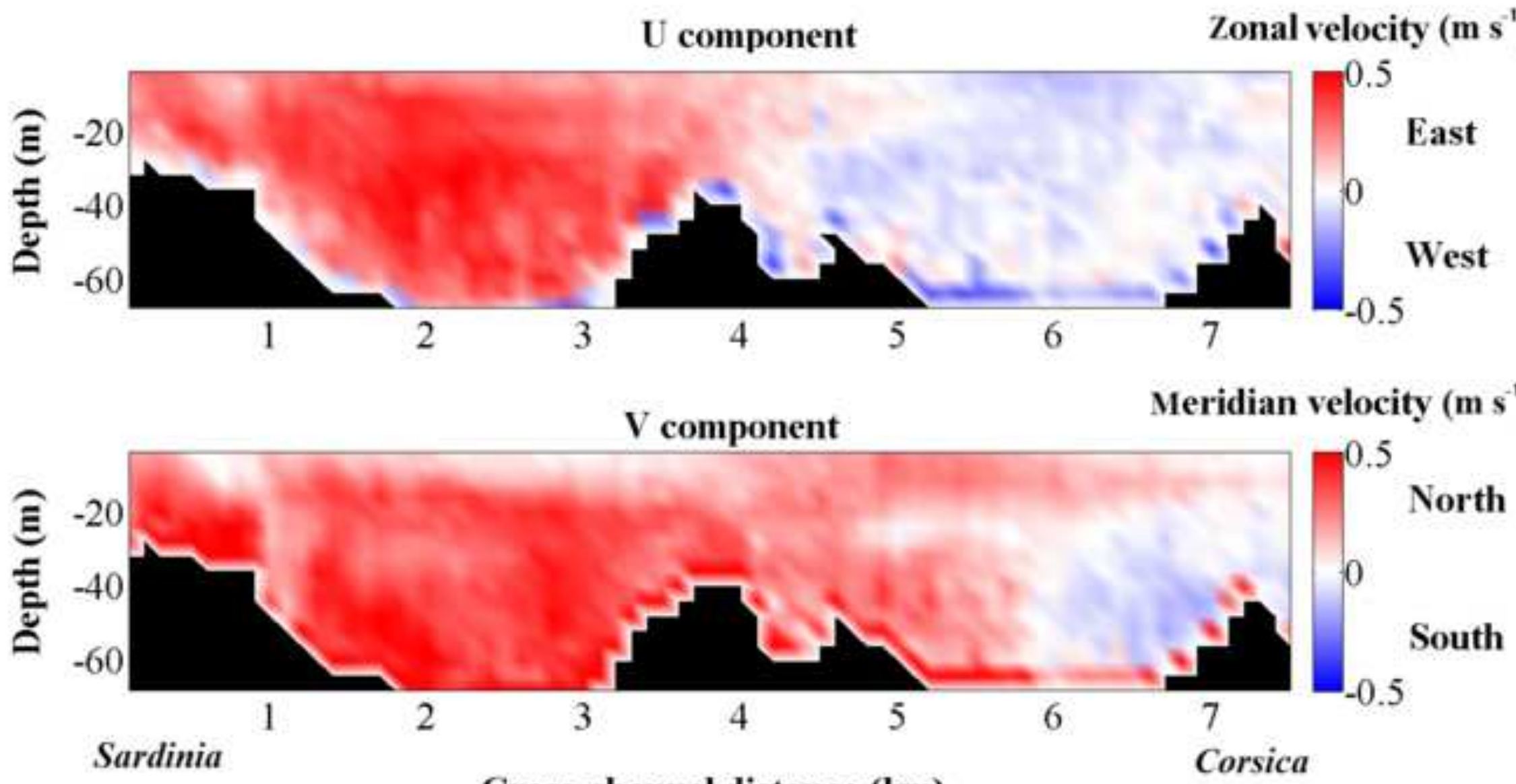

Cross-channel distance (km) 
Click here to download Manuscript: figure 6b model_p23 vrs6.TIF

Click here to view linked References

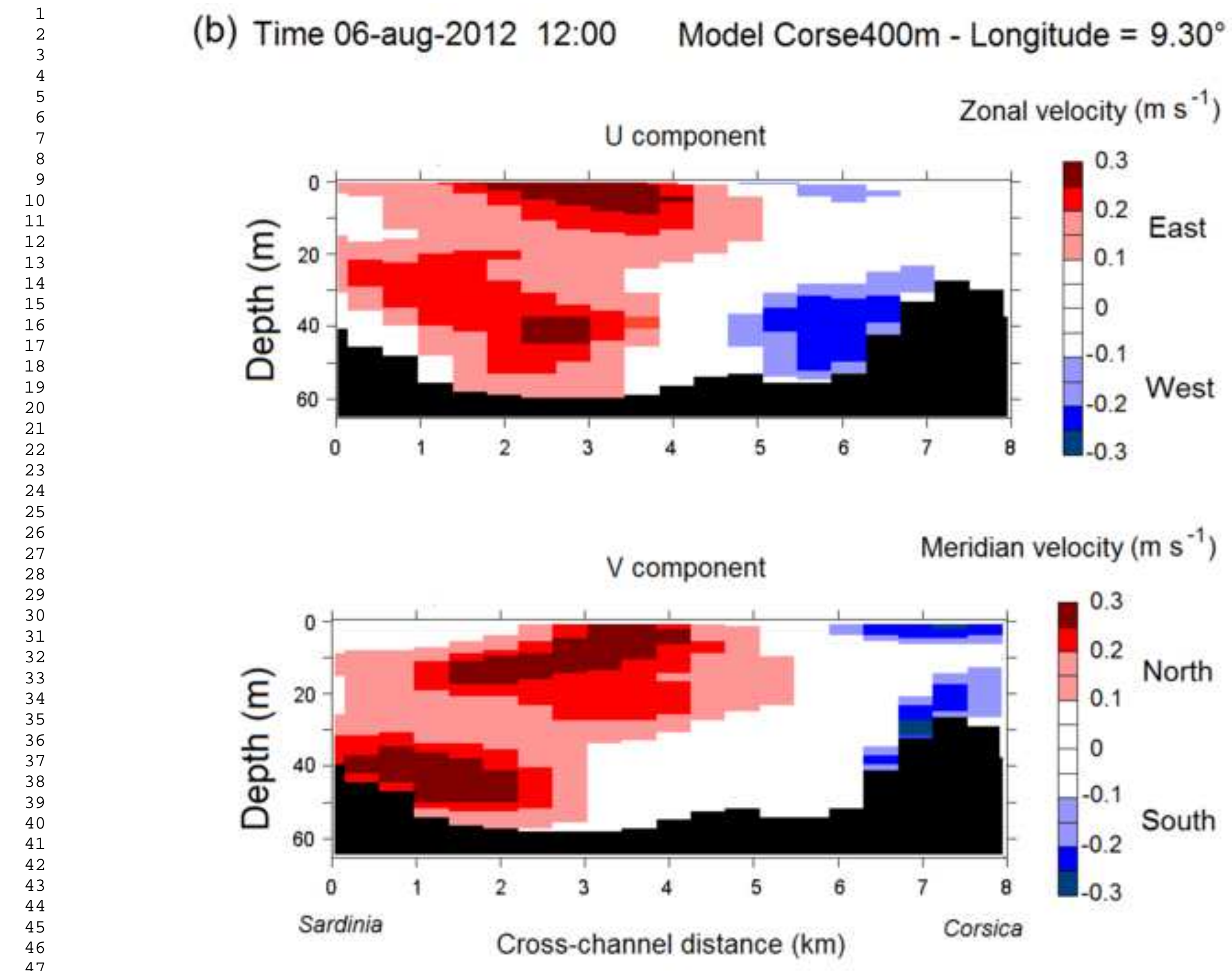

(b) Time 06-aug-2012 12:00 Model Corse400m - Longitude $=9.30^{\circ}$ 
figure_7

Click here to download Manuscript: fig 7 model_ouest_vrs4.tif

Click here to view linked References

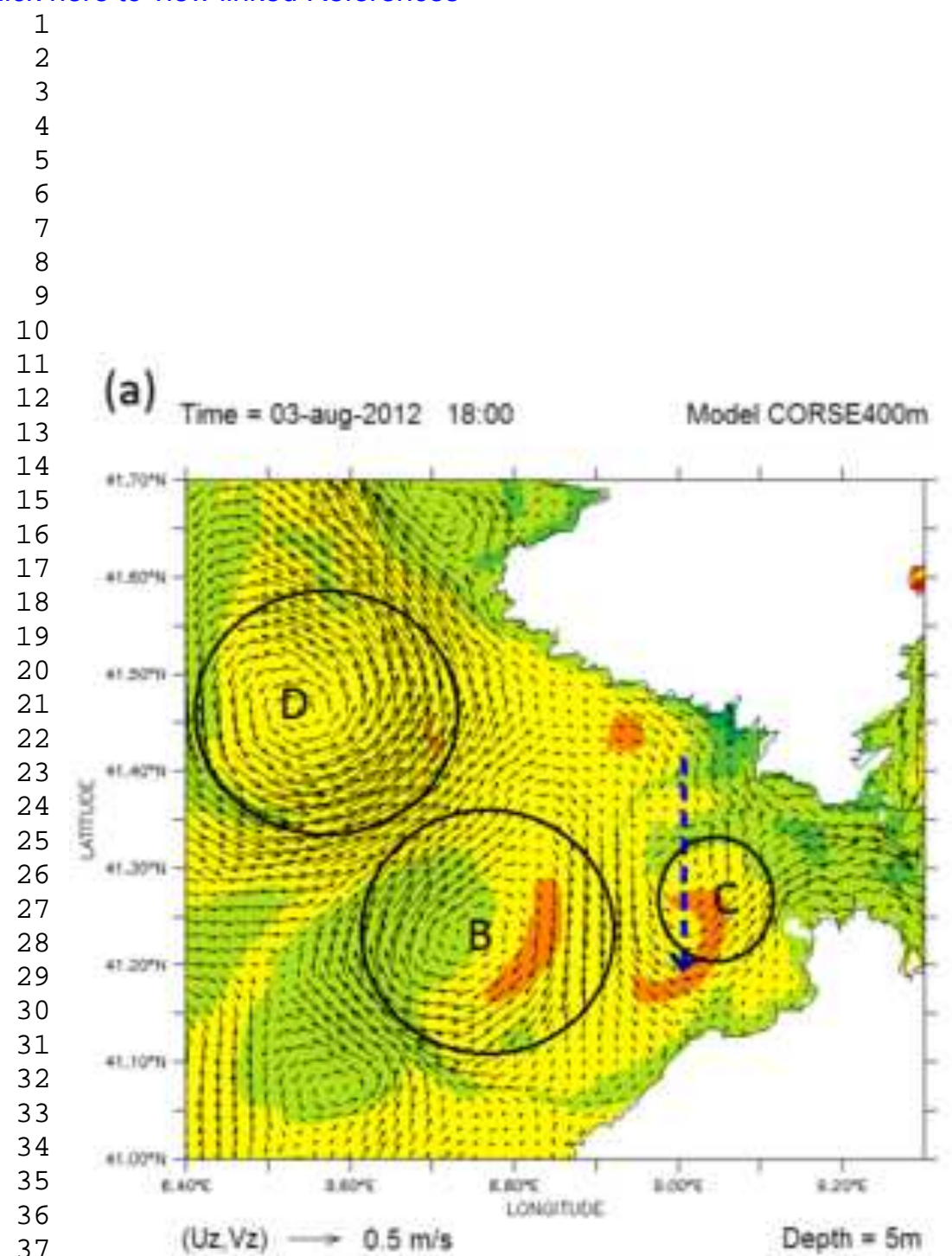

(b)

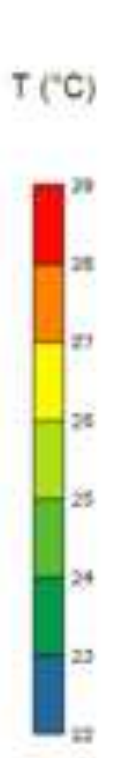

Time $=04-a u g-2012 \quad 03: 00$

Model CORSE $400 \mathrm{~m}$

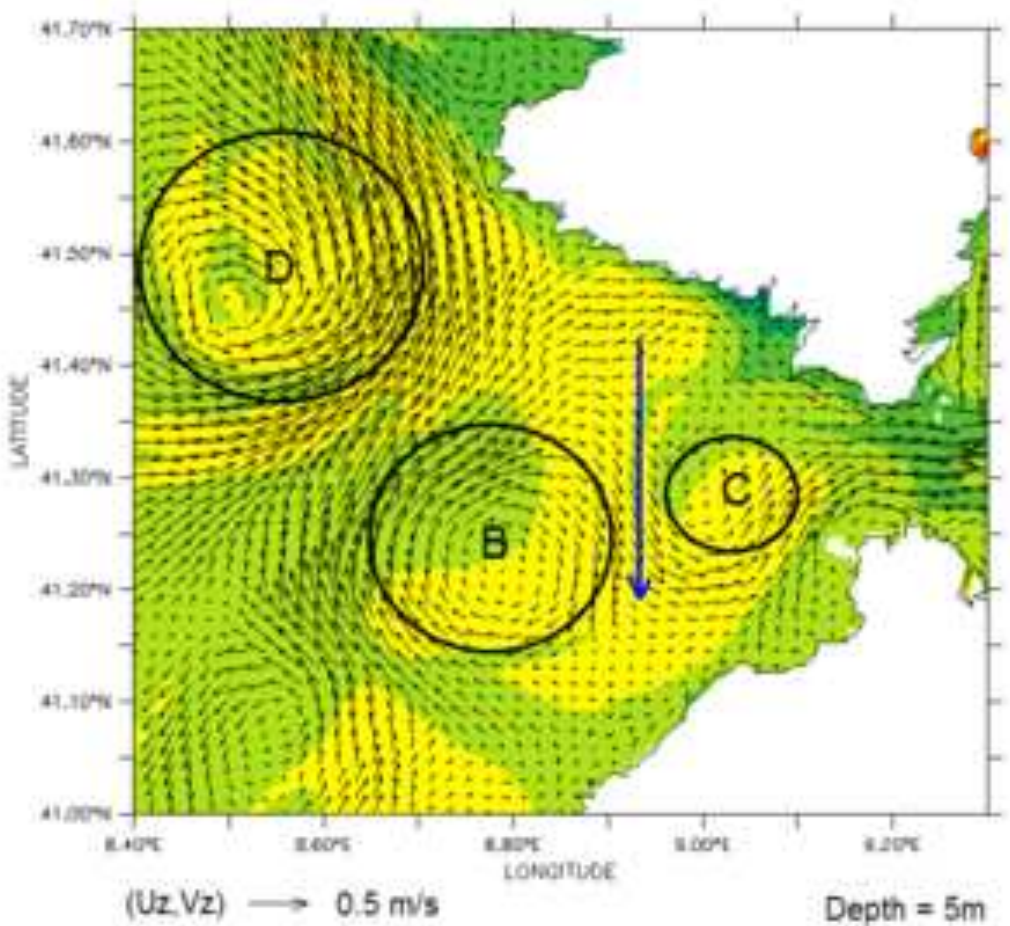


Click here to download Manuscript: fig_8a_bin2m_vrs6.TIF Click here to view linked References

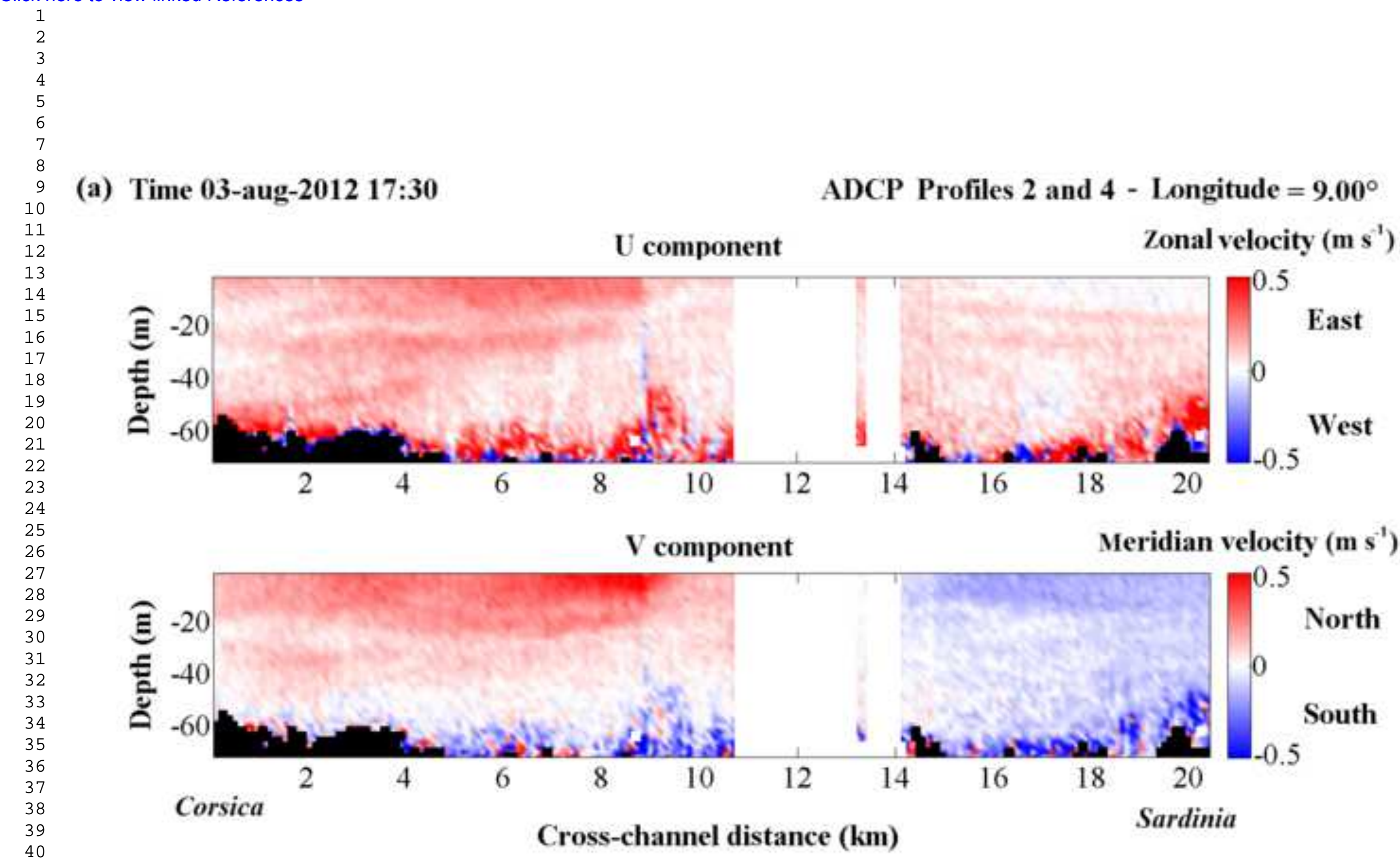
Zonal velocity $\left(\mathrm{m} \mathrm{s}^{-1}\right)$ 


\section{figure_9}

Click here to download Manuscript: fig_9_model_milieu_SoB_vrs7.TIF Click here to view linked References

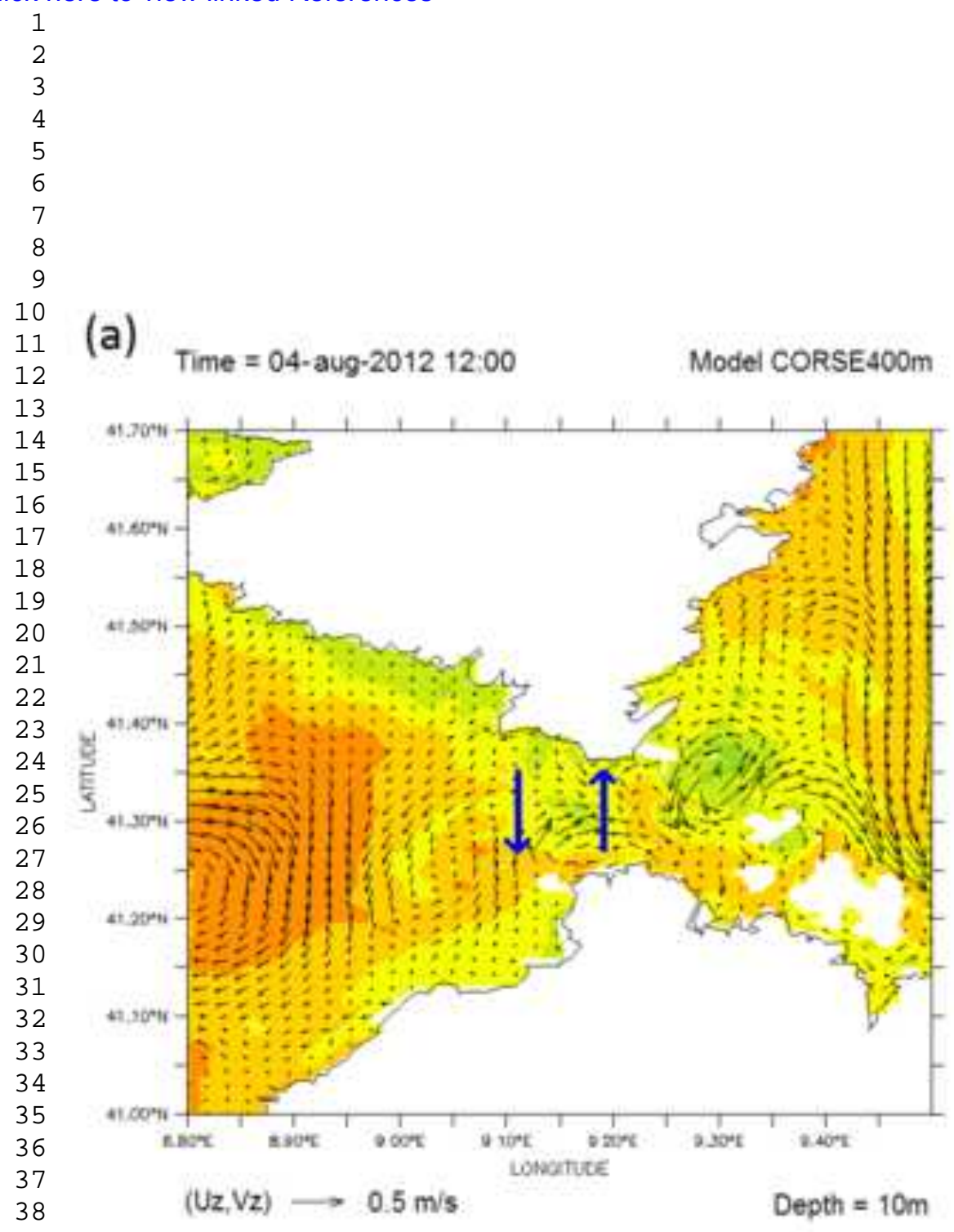

(b)

Time $=04-$ aug-2012 12:00

Model CORSE $400 \mathrm{~m}$
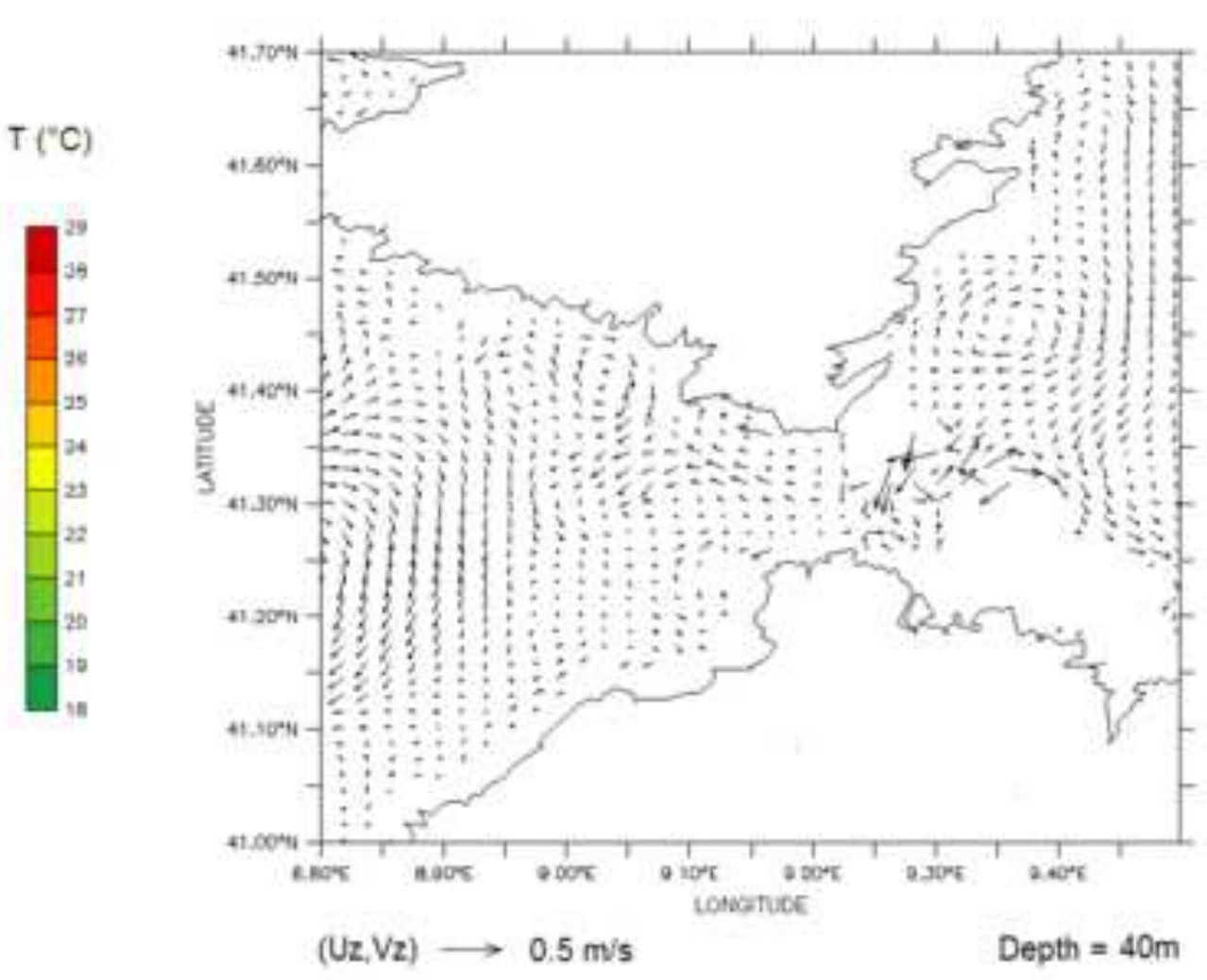

41

42

43

44

45

46

47 
Click here to download Manuscript: fig 10a bin2m vrs6.TIF

Click here to view linked References

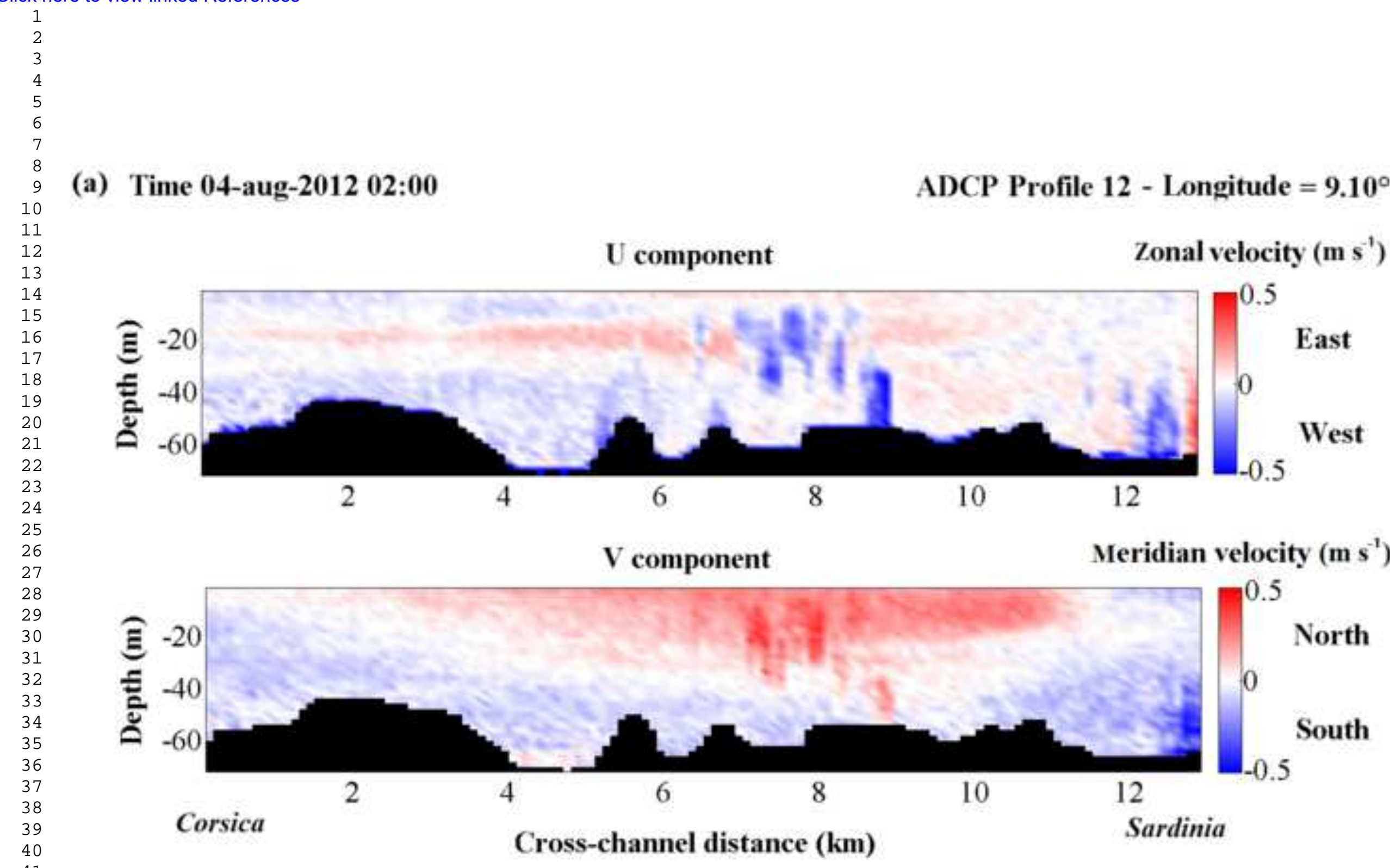


Click here to download Manuscript: fig_11a_bin2m_vrs6.TIF

Click here to view linked References

U component Zonal velocity ( $\left.\mathrm{m} \mathrm{s}^{-1}\right)$
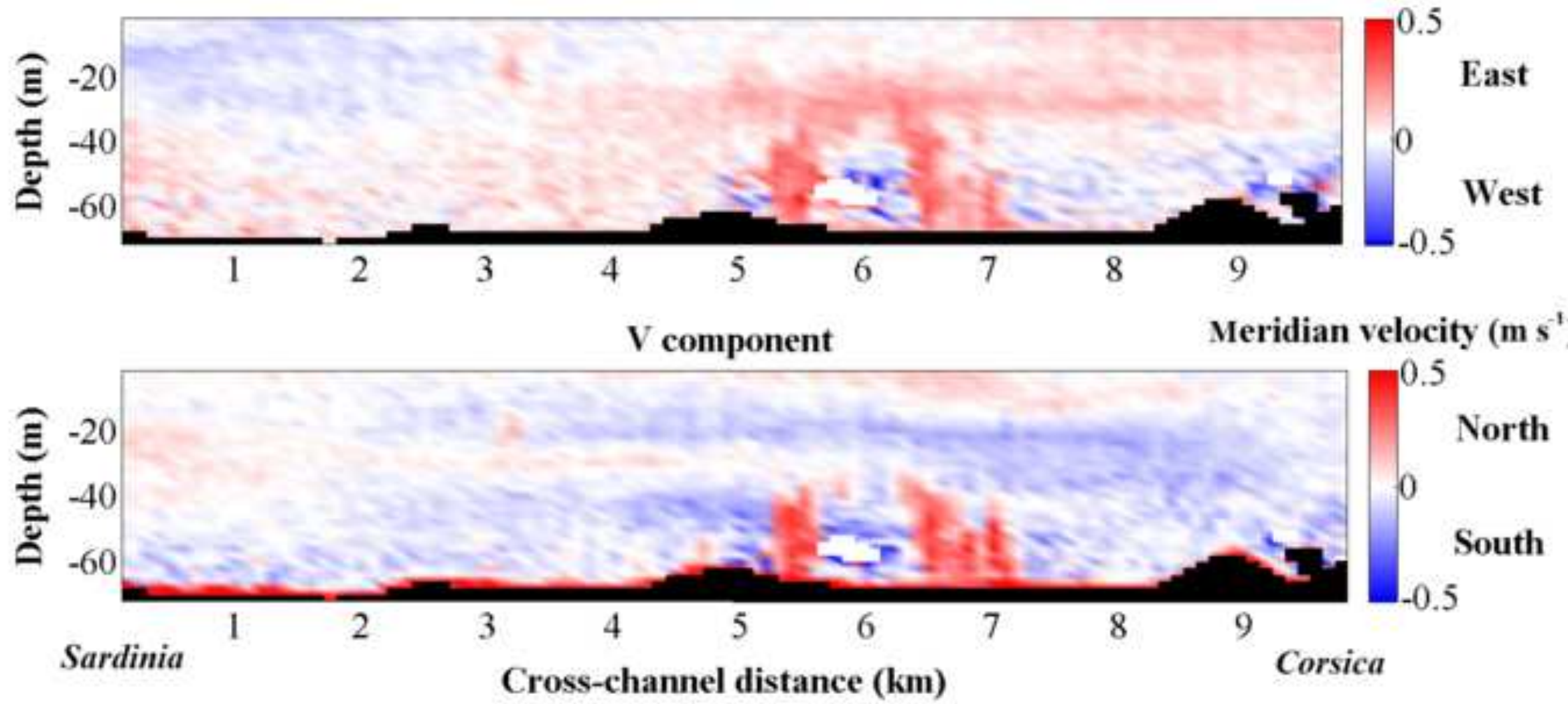


\section{figure 12}

Click here to download Manuscript: fig_12_tethys_vrsC.tif Click here to view linked References
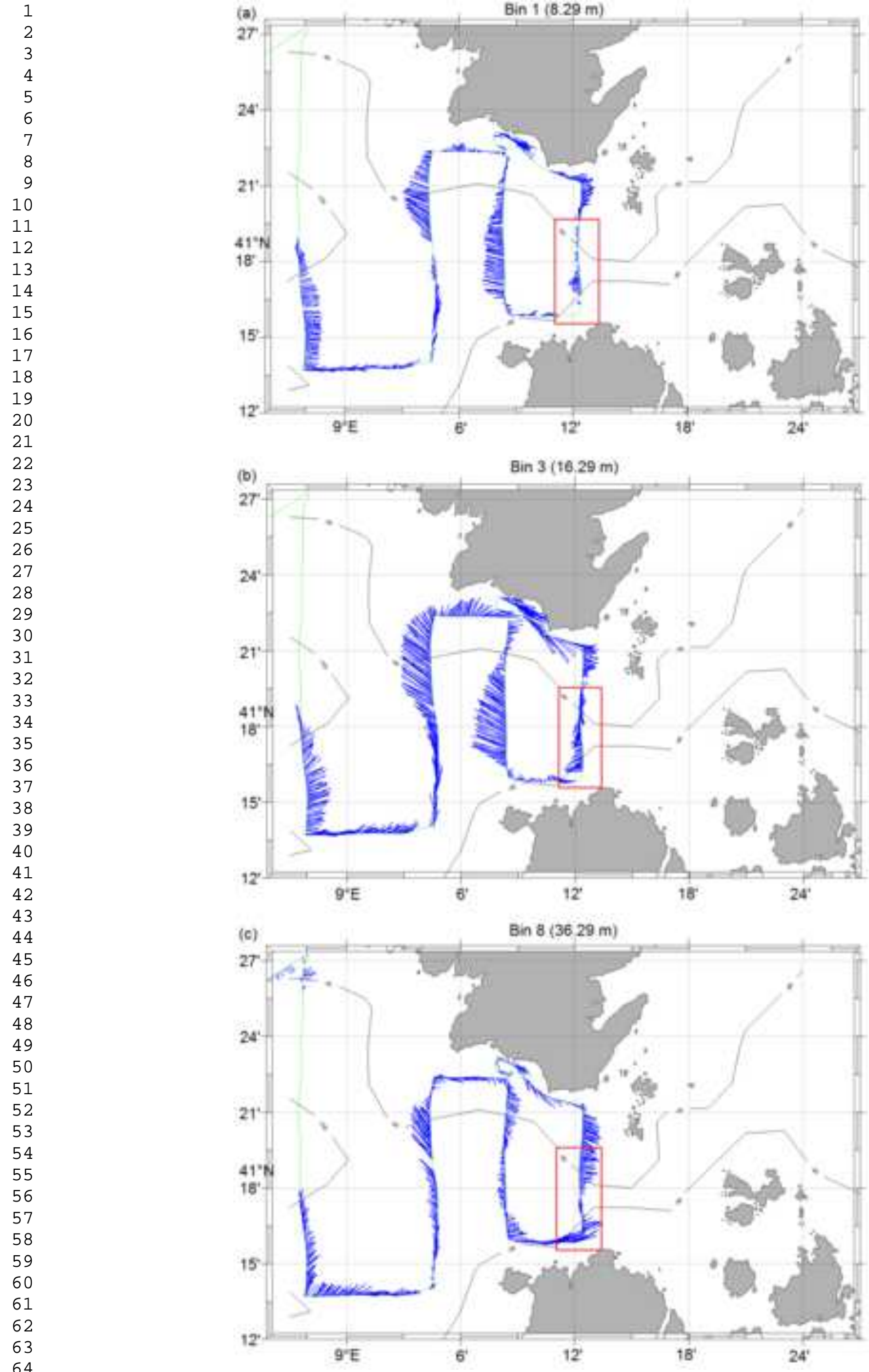
Click here to download Manuscript: Fig_14.a_vrs3.tif Click here to view linked References
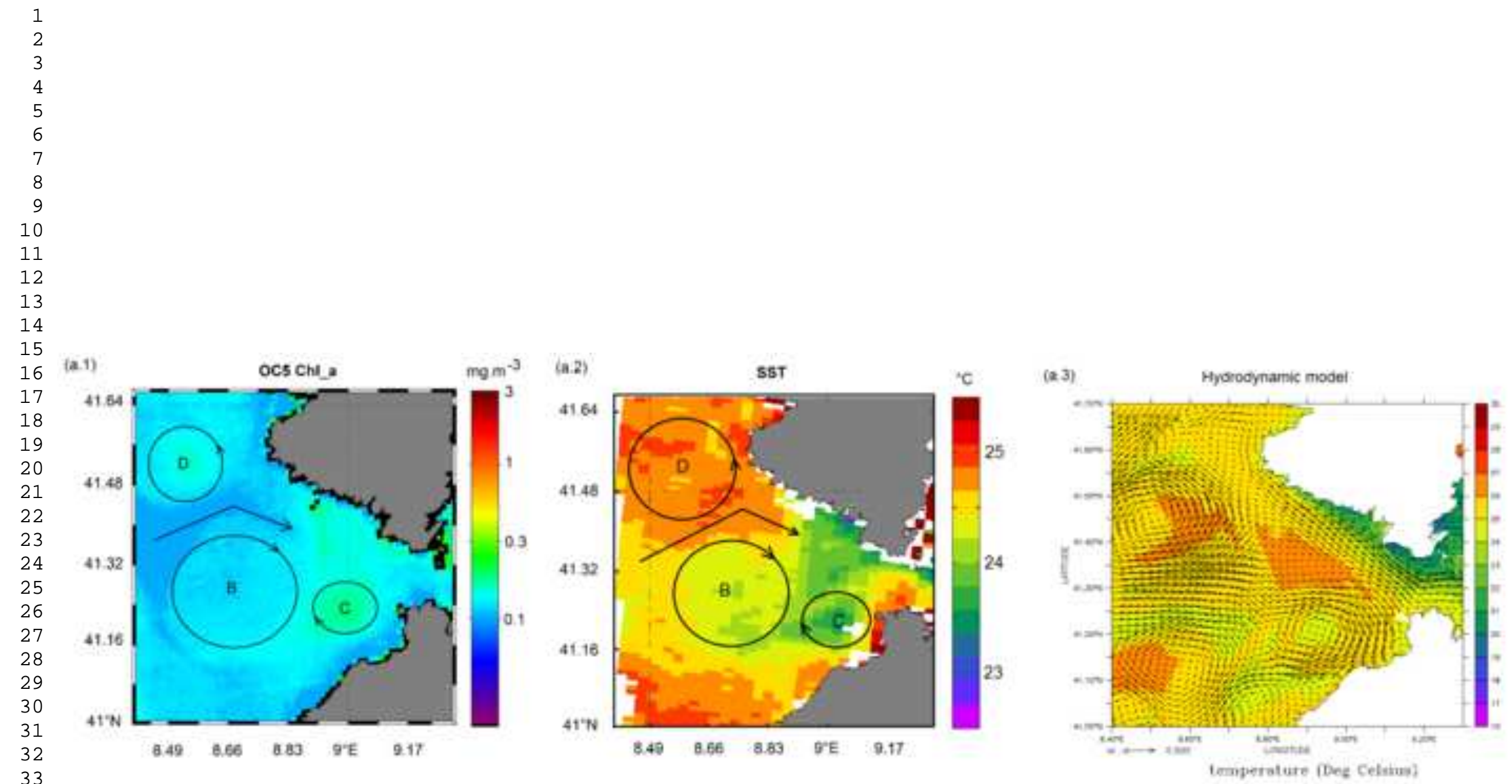


\section{figure_14b}

Click here to download Manuscript: Fig_14.b_vrs3.tif Click here to view linked References

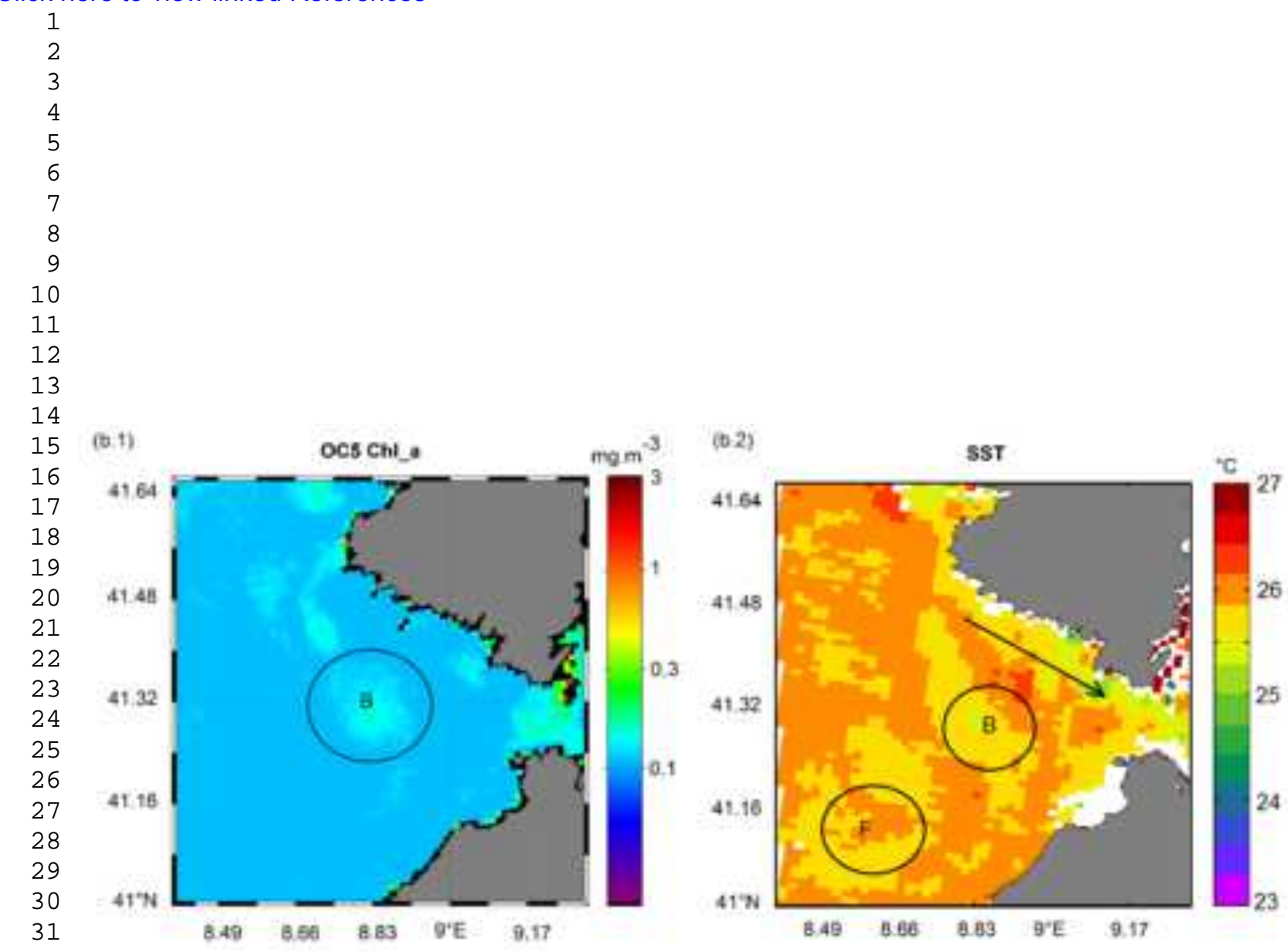

(b.3)

Hydrooynamic model

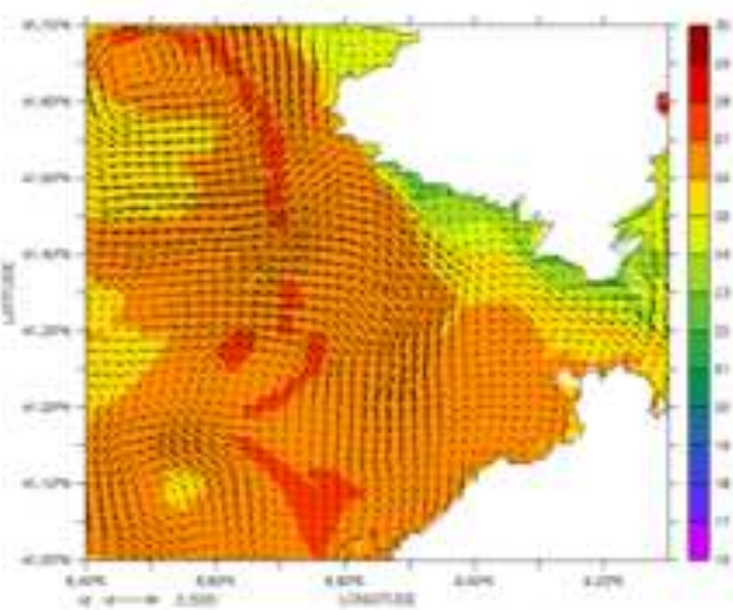

teraperature (Dee Celaius) 
Click here to download Manuscript: Fig_14.c_vrs2.tif Click here to view linked References
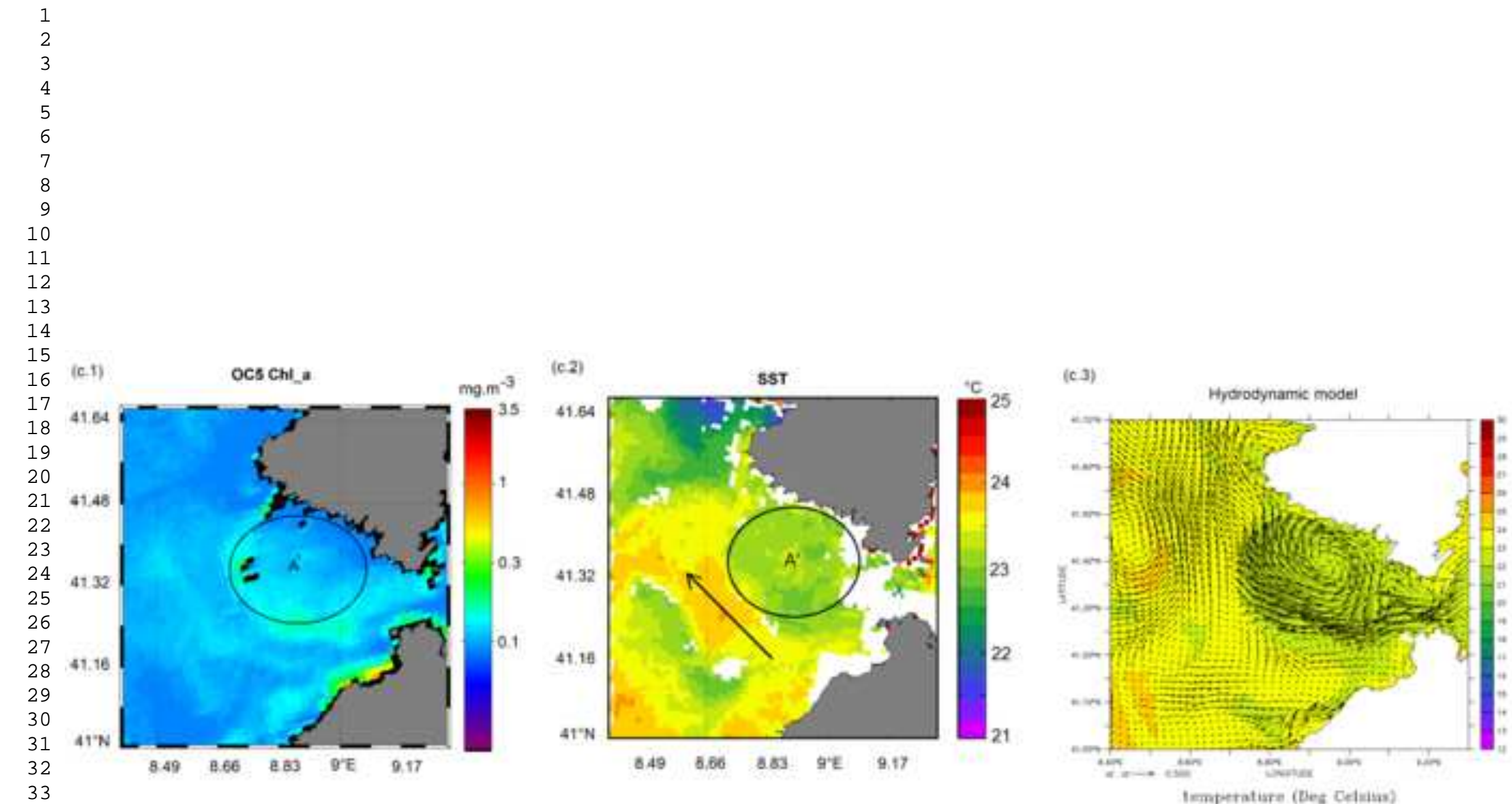

33

34

36

37

38

40

41

42

43

45

46

47

48

49 
table_1

Click here to download Manuscript: Table1Revised_vrs12.doc

Click here to view linked References

\begin{tabular}{|c|c|c|c|c|c|c|c|c|c|}
\hline & & & Zonal & ompc & $\operatorname{ent}\left(m s^{-1}\right)$ & Meridis & $\operatorname{comp}$ & nent $\left(\mathrm{m} \mathrm{s}^{-1}\right)$ & \\
\hline & & & AD & & Model & AD & & Model & \\
\hline Profile & Depth & $\begin{array}{l}\text { Section of } \\
\text { the profile } \\
\quad(\mathbf{k m})\end{array}$ & Mean & Std & $\begin{array}{c}\text { Main } \\
\text { current vein }\end{array}$ & Mean & Std & $\begin{array}{c}\text { Main } \\
\text { current vein }\end{array}$ & $\begin{array}{c}\text { Model } \\
\text { time shift }\end{array}$ \\
\hline $\mathbf{P} 2-\mathbf{P} 4$ & water column $(10-50 \mathrm{~m})$ & $0-10 \mathrm{~km}$ & +0.25 & 0.03 & +0.07 & +0.24 & 0.03 & +0.13 & $+9 \mathrm{~h}$ \\
\hline $12-14$ & water column $(10-50 \mathrm{~m})$ & $14-20 \mathrm{~km}$ & +0.09 & 0.05 & +0.11 & -0.20 & 0.07 & -0.10 & $+9 \mathrm{~h}$ \\
\hline P 12 & subsurface $(10-30 \mathrm{~m})$ & $4-6 \mathrm{~km}$ & +0.11 & 0.01 & +0.16 & +0.10 & 0.01 & +0.11 & $+9 \mathrm{~h}$ \\
\hline 112 & bottom $(40-60 \mathrm{~m})$ & $4-6 \mathrm{~km}$ & -0.05 & 0.04 & +0.003 & -0.09 & 0.03 & +0.006 & $+9 \mathrm{~h}$ \\
\hline P 14 & subsurface $(10-40 \mathrm{~m})$ & $4-7 \mathrm{~km}$ & +0.44 & 0.02 & +0.23 & -0.31 & 0.04 & -0.14 & $+6 \mathrm{~h}$ \\
\hline 114 & bottom $(40-60 \mathrm{~m})$ & $5-6 \mathrm{~km}$ & +0.35 & 0.17 & +0.01 & +0.27 & 0.33 & +0.16 & $+6 \mathrm{~h}$ \\
\hline & water column $(10-50 \mathrm{~m})$ & $0-4 \mathrm{~km}$ & +0.23 & 0.05 & +0.27 & +0.40 & 0.06 & +0.35 & $+1 \mathrm{~h}$ \\
\hline $\mathbf{P} 23$ & water column $(10-50 \mathrm{~m})$ & $4-6 \mathrm{~km}$ & -0.20 & 0.08 & -0.15 & +0.25 & 0.04 & -0.06 & $+1 \mathrm{~h}$ \\
\hline & water column $(10-50 \mathrm{~m})$ & $6-7 \mathrm{~km}$ & -0.09 & 0.03 & -0.19 & -0.12 & 0.05 & -0.22 & $+1 \mathrm{~h}$ \\
\hline
\end{tabular}




\begin{tabular}{|c|c|c|}
\hline $\begin{array}{c}\text { AGREEMENT BETWEEN } \\
\text { SATELLITE DATA AND } \\
\text { MODEL }\end{array}$ & $\begin{array}{c}\text { NUMBER OF } \\
\text { IMAGES }\end{array}$ & WIND FROM MODEL \\
\hline \multicolumn{3}{|c|}{ July 2012} \\
\hline No vortex identified & 1 & South East to West wind \\
\hline One vortex identified & 4 & West wind \\
\hline Double vortex system identified & 1 & West wind \\
\hline \multicolumn{3}{|c|}{ August 2012} \\
\hline No vortex identified & 1 & West wind \\
\hline One vortex identified & 4 & West wind \\
\hline Double vortex system identified & 4 & South East to South West Wind \\
\hline & September 2012 & South East to South West Wind \\
\hline No vortex identified & 2 & South East to South West Wind \\
\hline One vortex identified & 1 &
\end{tabular}

